ARTICLE

\title{
Isolated copper single sites for high-performance electroreduction of carbon monoxide to multicarbon products
}

\author{
Haihong Bao ${ }^{1,11}$, Yuan Qiu ${ }^{1,11}$, Xianyun Peng ${ }^{1,11}$, Jia-ao Wang ${ }^{2,11}$, Yuying Mi', Shunzheng Zhao ${ }^{3}$,

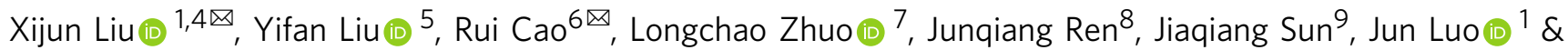 \\ Xuping Sun (1D ${ }^{10 \times}$
}

Electrochemical carbon monoxide reduction is a promising strategy for the production of value-added multicarbon compounds, albeit yielding diverse products with low selectivities and Faradaic efficiencies. Here, copper single atoms anchored to $\mathrm{Ti}_{3} \mathrm{C}_{2} \mathrm{~T}_{x} \mathrm{MXene}$ nanosheets are firstly demonstrated as effective and robust catalysts for electrochemical carbon monoxide reduction, achieving an ultrahigh selectivity of $98 \%$ for the formation of multicarbon products. Particularly, it exhibits a high Faradaic efficiency of $71 \%$ towards ethylene at $-0.7 \mathrm{~V}$ versus the reversible hydrogen electrode, superior to the previously reported copper-based catalysts. Besides, it shows a stable activity during the 68-h electrolysis. Theoretical simulations reveal that atomically dispersed $\mathrm{Cu}-\mathrm{O}_{3}$ sites favor the $\mathrm{C}-\mathrm{C}$ coupling of carbon monoxide molecules to generate the key ${ }^{\star} \mathrm{CO}-\mathrm{CHO}$ species, and then induce the decreased free energy barrier of the potential-determining step, thus accounting for the high activity and selectivity of copper single atoms for carbon monoxide reduction.

\footnotetext{
${ }^{1}$ Institute for New Energy Materials \& Low-Carbon Technologies and Tianjin Key Lab of Photoelectric Materials \& Devices, School of Materials Science and Engineering, Tianjin University of Technology, Tianjin 300384, China. ${ }^{2}$ School of Material Science and Engineering, University of Jinan, Jinan 250022, China. ${ }^{3}$ Department of Environmental Engineering, University of Science and Technology Beijing, Beijing 100083, China. ${ }^{4}$ Key Laboratory of Civil Aviation Thermal Hazards Prevention and Emergency Response, Civil Aviation University of China, Tianjin 300300, China. ${ }^{5}$ College of Physics and Optoelectronic Engineering, Shenzhen University, Shenzhen 518060, China. ${ }^{6}$ Stanford Synchrotron Radiation Lightsource, SLAC National Accelerator Laboratory, Menlo Park, CA 94025, United States. ${ }^{7}$ School of Materials Science and Engineering, Xi'an University of Technology, Xi'an 710048 Shanxi, China. ${ }^{8}$ State Key Laboratory of Advanced Processing and Recycling of Nonferrous Metals, Lanzhou University of Technology, Lanzhou 730050 Gansu, China. ${ }^{9}$ State Key Laboratory of Coal Conversion, Institute of Coal Chemistry, Chinese Academy of Sciences, Taiyuan 030001 Shanxi, China. ${ }^{10}$ Institute of Fundamental and Frontier Sciences, University of Electronic Science and Technology of China, Chengdu 610054 Sichuan, China. ${ }^{11}$ These authors contributed equally: Haihong Bao, Yuan Qiu,

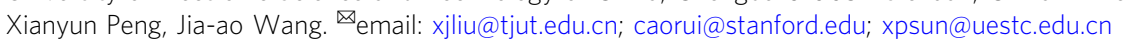


$\mathrm{T}$ he electrochemical $\mathrm{CO}_{2}$ reduction $\left(\mathrm{CO}_{2} \mathrm{R}\right)$, as an appealing approach toward $\mathrm{CO}_{2}$ mitigation and artificial carbon recycling, has been extensively studied in recent years ${ }^{1-4}$. However, effective strategies for the direct reduction of $\mathrm{CO}_{2}$ to more value-added $\mathrm{C}_{2}$ products are not available at present due to the relatively low selectivity. In contrast, a wealth of efficient and selective electrocatalysts have been developed for the reduction of $\mathrm{CO}_{2}$ to $\mathrm{CO}$ as the primary product, achieving a Faradaic efficiency (FE) larger than $90 \%^{5-7}$. In this regard, the further electrochemical CO reduction (COR) is desirable for deriving more value-added $\mathrm{C}_{2+}$ products ${ }^{6,8-10}$.

Abundant efforts have been made in developing efficient COR catalysts $^{11-13}$, however, to date, copper $(\mathrm{Cu})$-based materials are still the only known metal catalysts for electrochemically converting $\mathrm{CO}$ into multicarbon hydrocarbons and oxygenates, like $\mathrm{C}_{2} \mathrm{H}_{4}$ and $\mathrm{C}_{2} \mathrm{H}_{5} \mathrm{OH}(\mathrm{EtOH})$, with an appreciable activity ${ }^{14-17}$. Generally, the stepped or kinked surfaces, as well as grain boundary surface terminations in polycrystalline $\mathrm{Cu}$ and oxidederived $\mathrm{Cu}$ species ${ }^{11,18,19}$, are considered to be active for COR. However, the structural complexity of these $\mathrm{Cu}$ species imposes a lot of difficulties to identify the exact sites responsible for their catalytic properties. Moreover, the diverse active centers of $\mathrm{Cu}$ species lead to unsatisfactory FEs and selectivities of the desired products because of various undetermined reaction pathways and competing hydrogen evolution reaction (HER). In contrast, single-atom (SA) catalysts exhibit unique active centers that can acquire an exceptional activity and selectivity in those electrocatalysis reactions involving multiple pathways ${ }^{20-23}$. Therefore, SA-based materials present potentially promising alternative catalysts, although they have never been scrutinized as COR electrocatalysts until now.

Recently, the two-dimensional (2D) materials, as a powerful platform to support SA catalysts, have attracted great attention because of large specific surface areas, more exposed active sites, and superior catalytic activities ${ }^{24-30}$. Particularly, with excellent electronic conductivity, catalytically active basal planes, and graphene-like unique layered structures, $2 \mathrm{D} \mathrm{Ti}_{3} \mathrm{C}_{2} \mathrm{~T}_{x}$ MXene $\left(\mathrm{T}_{x}\right.$ represents surface functional groups) has been investigated extensively for a variety of electrochemical reactions ${ }^{31-33}$. More importantly, it has a unique feature of a high reducing capability, suitable surface defects, and hydrophilic surface functionalities, which make it an ideal candidate to support and stabilize $\mathrm{SAs}^{34,35}$.

In this work, we disclose the synthesis, characterization, and COR activity of the $\mathrm{Cu}$ SA catalyst stabilized on $2 \mathrm{D} \mathrm{Ti}_{3} \mathrm{C}_{2} \mathrm{~T}_{x}$ nanosheets. The supported $\mathrm{Cu} \mathrm{SA}$ catalysts corresponded to $\mathrm{O}$-coordinated $\mathrm{Cu}$ sites on $\mathrm{Ti}_{3} \mathrm{C}_{2} \mathrm{~T}_{x}$ matrix $\left(\mathrm{Cu}-\mathrm{SA} / \mathrm{Ti}_{3} \mathrm{C}_{2} \mathrm{~T}_{x}\right)$, as revealed by X-ray absorption fine structure (XAFS) analysis. Computational studies confirmed the outstanding stability of $\mathrm{Cu}$ SAs on $\mathrm{Ti}_{3} \mathrm{C}_{2} \mathrm{~T}_{x}$. When applied in $\mathrm{COR}, \mathrm{Cu}-\mathrm{SA} / \mathrm{Ti}_{3} \mathrm{C}_{2} \mathrm{~T}_{x}$ shows unprecedented selectivity ( $98 \%$ total) in the formation of $\mathrm{C}_{2}$ products, which is much higher than its counterpart of $\mathrm{Cu}-\mathrm{NP} /$ $\mathrm{Ti}_{3} \mathrm{C}_{2} \mathrm{~T}_{x}$. Outstandingly, the maximum FE of $71 \%$ towards $\mathrm{C}_{2} \mathrm{H}_{4}$ is achieved at $-0.7 \mathrm{~V}$ versus the reversible hydrogen electrode (vs RHE), representing one of the highest values among the reported Cu-based COR catalysts ${ }^{1,5,8-13}$. Furthermore, $\mathrm{Cu}$ $\mathrm{SA} / \mathrm{Ti}_{3} \mathrm{C}_{2} \mathrm{~T}_{x}$ presents high electrochemical stability over $68 \mathrm{~h}$. Theoretical analysis of pathways for $\mathrm{C}_{2} \mathrm{H}_{4}$ and $\mathrm{EtOH}$ formation gives an in-depth understanding of the enhanced reactivity and selectivity of $\mathrm{Cu}-\mathrm{SA} / \mathrm{Ti}_{3} \mathrm{C}_{2} \mathrm{~T}_{x}$ compared with $\mathrm{Cu}$ nanoparticles.

\section{Results}

Synthesis and characterization of $\mathrm{Cu}-\mathrm{SA} / \mathrm{Ti}_{3} \mathrm{C}_{2} \mathrm{~T}_{x}$. As illustrated in Fig. 1a, ultrathin $\mathrm{Ti}_{3} \mathrm{C}_{2} \mathrm{~T}_{x}$ nanosheets were prepared from parent $\mathrm{Ti}_{3} \mathrm{AlC}_{2}$ via etching in a mixed solution of $\mathrm{HCl}$ and $\mathrm{LiF}$, and $\mathrm{Cu}-\mathrm{SA} / \mathrm{Ti}_{3} \mathrm{C}_{2} \mathrm{~T}_{x}$ was achieved by a one-step synthesis strategy (see the Methods section for more details). The X-ray diffraction (XRD) pattern of $\mathrm{Cu}-\mathrm{SA} / \mathrm{Ti}_{3} \mathrm{C}_{2} \mathrm{~T}_{x}$, as shown in Fig. 1b, reveals a crystal structure similar to that of $\mathrm{Ti}_{3} \mathrm{C}_{2} \mathrm{~T}_{x}$ (ref. ${ }^{33}$ ). No diffraction peaks of any $\mathrm{Cu}$ species are observed, indicating the good dispersion of $\mathrm{Cu}$ SAs on $\mathrm{Ti}_{3} \mathrm{C}_{2} \mathrm{~T}_{x}$. High-angle annular dark-field scanning transmission electron microscopy (HAADF-STEM) and transmission electron microscopy (TEM) images clearly indicate a nanosheet morphology of the as-synthesized $\mathrm{Cu}-\mathrm{SA} / \mathrm{Ti}_{3} \mathrm{C}_{2} \mathrm{~T}_{x}$ (Supplementary Figs. 1, 2 and Fig. 1c). $\mathrm{Cu}-\mathrm{SA} / \mathrm{Ti}_{3} \mathrm{C}_{2} \mathrm{~T}_{x}$ exhibits some interlayer-stacked mesopores resulting from the nanosheet structure (Supplementary Fig. 3), which improves the accessibility of active sites, and thus, the overall catalytic performance of the catalys $^{36}$. No Cu particles are visible in the TEM images (Fig. 1c and Supplementary Fig. 2), which correlates well with the XRD results (Fig. 1b). Atomic-resolution HAADF-STEM images (Fig. 1d and Supplementary Fig. 4) taken from randomly selected regions show individual $\mathrm{Cu}$ atoms (sharp bright dots) uniformly dispersed on the $\mathrm{Ti}_{3} \mathrm{C}_{2} \mathrm{~T}_{x}$ crystal lattice fringes. The presence of $\mathrm{Cu}$ SAs can also be confirmed by the simulated HAADF-STEM images in Supplementary Fig. 5 and comparisons with the images of $\mathrm{Ti}_{3} \mathrm{C}_{2} \mathrm{~T}_{x}$ support in Supplementary Fig. 6. Besides, statistical analysis indicated that the average distance between each $\mathrm{Cu}$ atom is determined to be $0.61 \mathrm{~nm}$ (Supplementary Fig. 7), much higher than that of $\mathrm{Cu}-\mathrm{Cu}$ bond $(\sim 0.27 \mathrm{~nm})$ in $\mathrm{Cu}$ dimers. Even a small number of $\mathrm{Cu}$ pairs $(<4 \%)$ are potentially formed, but such a small portion does very little contribution to the high COR activity. Energy-dispersive X-ray spectroscopy (EDX) further demonstrates the homogenous distribution of $\mathrm{Ti}, \mathrm{C}, \mathrm{O}$, and $\mathrm{Cu}$ atoms over the $\mathrm{Cu}-\mathrm{SA} / \mathrm{Ti}_{3} \mathrm{C}_{2} \mathrm{~T}_{x}$ surface (Supplementary Fig. 8). A $\mathrm{Cu}$ loading of $0.2 \mathrm{wt} \%$ was determined by inductively coupled plasma optical emission spectrometry (ICP-OES). In addition, when more $\mathrm{Cu}$ precursor was added, the co-existence of $\mathrm{Cu} \mathrm{SAs}$ and abundant $\mathrm{Cu}$ nanoclusters could be observed in the $\mathrm{Ti}_{3} \mathrm{C}_{2} \mathrm{~T}_{x}$ support (denoted as $\mathrm{Cu}-\mathrm{NC} / \mathrm{Ti}_{3} \mathrm{C}_{2} \mathrm{~T}_{x}$, Supplementary Fig. 9).

The chemical structure of $\mathrm{Cu}$ anchored to $\mathrm{Ti}_{3} \mathrm{C}_{2} \mathrm{~T}_{x}$ was further confirmed by X-ray photoelectron spectrometry (XPS) and X-ray absorption spectroscopy (XAS). The $\mathrm{Cu} 2 p$ XPS spectrum of $\mathrm{Cu}-$ $\mathrm{SA} / \mathrm{Ti}_{3} \mathrm{C}_{2} \mathrm{~T}_{x}$ (Supplementary Fig. 10) reveals binding energies of 932.5 and $952.4 \mathrm{eV}$ for $\mathrm{Cu} 2 p_{1 / 2}$ and $2 p_{3 / 2}$ orbitals, respectively, which are close to those of $\mathrm{Cu}^{0}$ or $\mathrm{Cu}^{1+}$ (refs. ${ }^{37,38}$ ). X-ray absorption near-edge structure (XANES) and extended X-ray absorption fine structure (EXAFS), which have been widely used for characterizing the SA catalysts in pioneering works 39,40 , were performed at the $\mathrm{Cu}$ K-edge. The $\mathrm{Cu}$ foil, $\mathrm{Cu}_{2} \mathrm{O}$, and $\mathrm{CuO}$ were also tested as a comparison to $\mathrm{Cu}-\mathrm{SA} / \mathrm{Ti}_{3} \mathrm{C}_{2} \mathrm{~T}_{x}$. The XANES profiles (Fig. 1e) suggest that the $\mathrm{Cu}$ valence state in $\mathrm{Cu}-\mathrm{SA} /$ $\mathrm{Ti}_{3} \mathrm{C}_{2} \mathrm{~T}_{x}$ is likely to be higher than that of metallic $\mathrm{Cu}^{0}$ but lower than that of $\mathrm{Cu}^{1+}$. The Fourier transform-EXAFS (FT-EXAFS) curve of $\mathrm{Cu}-\mathrm{SA} / \mathrm{Ti}_{3} \mathrm{C}_{2} \mathrm{~T}_{x}$ (Fig. 1f) shows one main peak at about $1.6 \AA$, and no prominent $\mathrm{Cu}-\mathrm{Cu}$ back-scattering peak $(2.2 \AA$, existed in $\mathrm{Cu}$ foil EXAFS spectra) is observed ${ }^{23,41}$. The wavelet transform (WT) contour plot of the $\mathrm{Cu}$ K-edge EXAFS oscillations of $\mathrm{Cu}-\mathrm{SA} / \mathrm{Ti}_{3} \mathrm{C}_{2} \mathrm{~T}_{x}$ (Supplementary Fig. 11) shows one intensity maximum at $4.0 \AA^{-1}$ associated with the $\mathrm{Cu}-\mathrm{O}$ path in the first coordination shell. Compared with the WT plot of the $\mathrm{Cu}$ foil, no intensity maximum is detected near $7.7 \AA^{-1}$ (corresponding to the $\mathrm{Cu}-\mathrm{Cu}$ path), this provides further evidence for the atomic dispersion of $\mathrm{Cu}$ atoms. According to the fitting results shown in Fig. 1g and Supplementary Fig. 12, the main peak at $\sim 1.6 \AA$ is associated with the nearest $\mathrm{O}$ coordination shell of the $\mathrm{Cu}-\mathrm{SA} / \mathrm{Ti}_{3} \mathrm{C}_{2} \mathrm{~T}_{x}$ catalyst (phase uncorrected). The small bulge at a radical distance of $\sim 2.7 \AA$ is associated with the scattering path of the second shell $\mathrm{Ti}$, which is in agreement with the theoretical optimized model (inset of Fig. 1g). The fitted parameters are listed in Supplementary Table 1 and the coordination number of $\mathrm{O}$ is $\sim 3$. Therefore, $\mathrm{Cu}-\mathrm{O}_{3}$ sites formed 


\section{a}
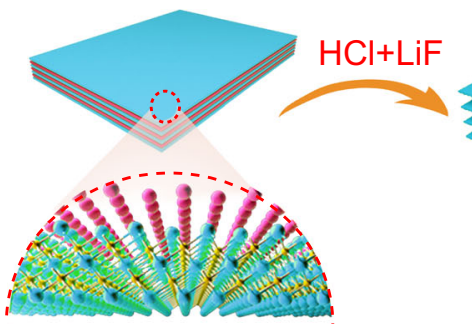

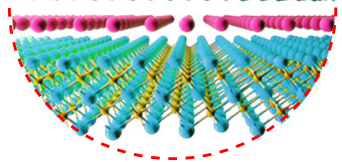

$\mathrm{Ti}_{3} \mathrm{AlC}_{2}$
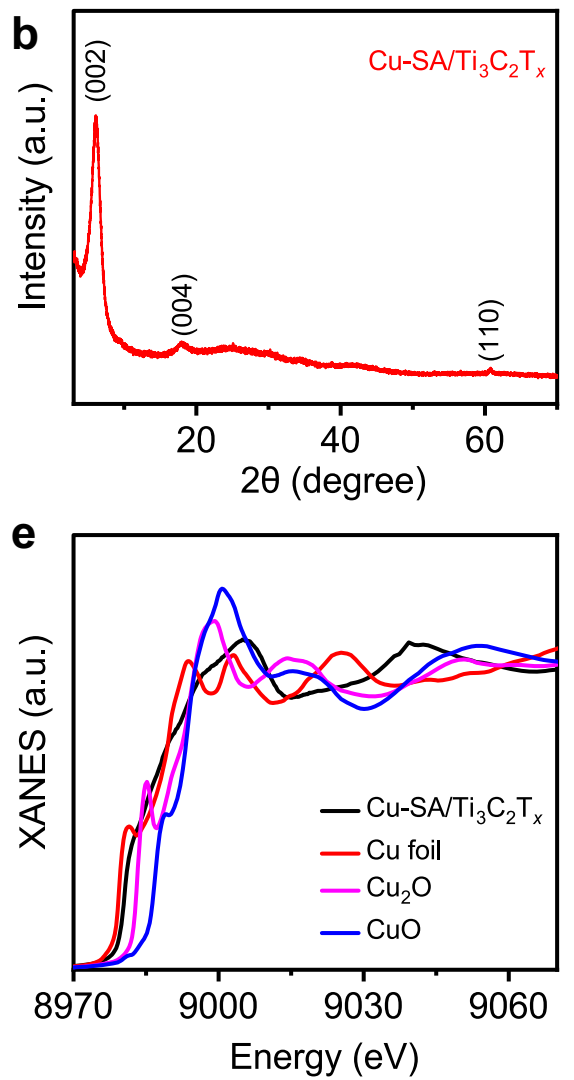
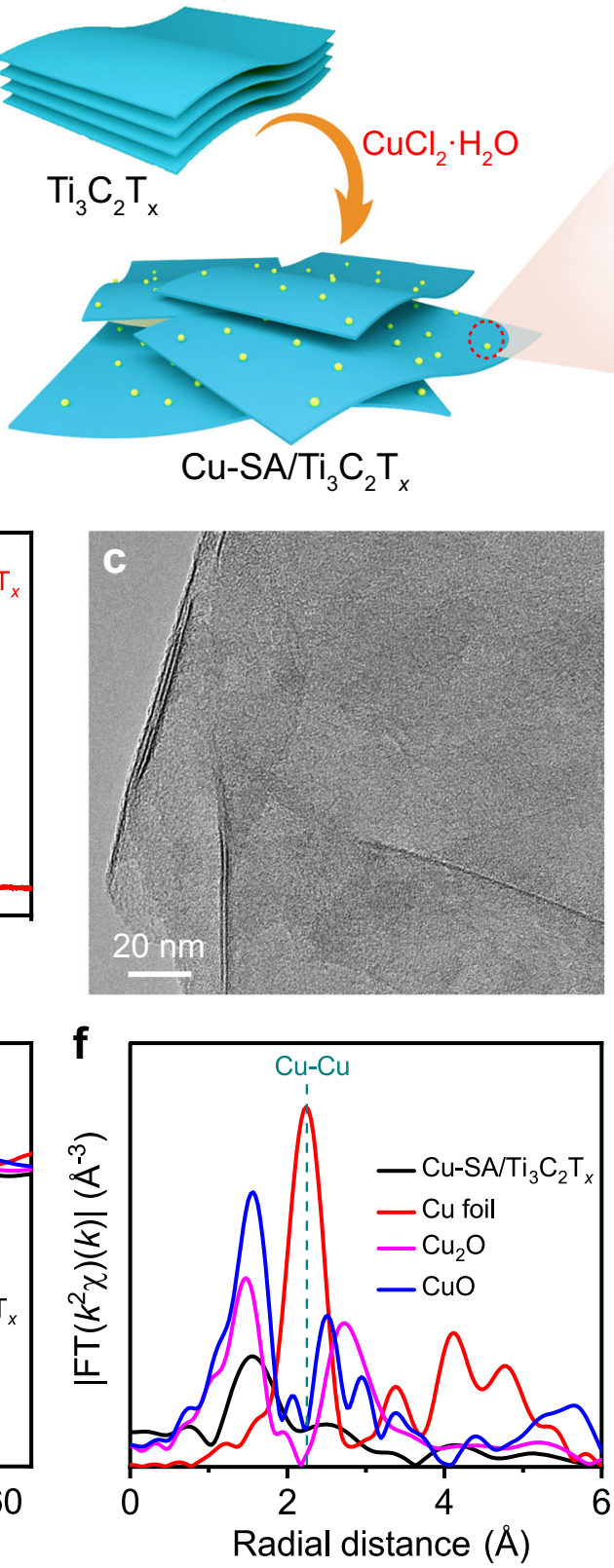
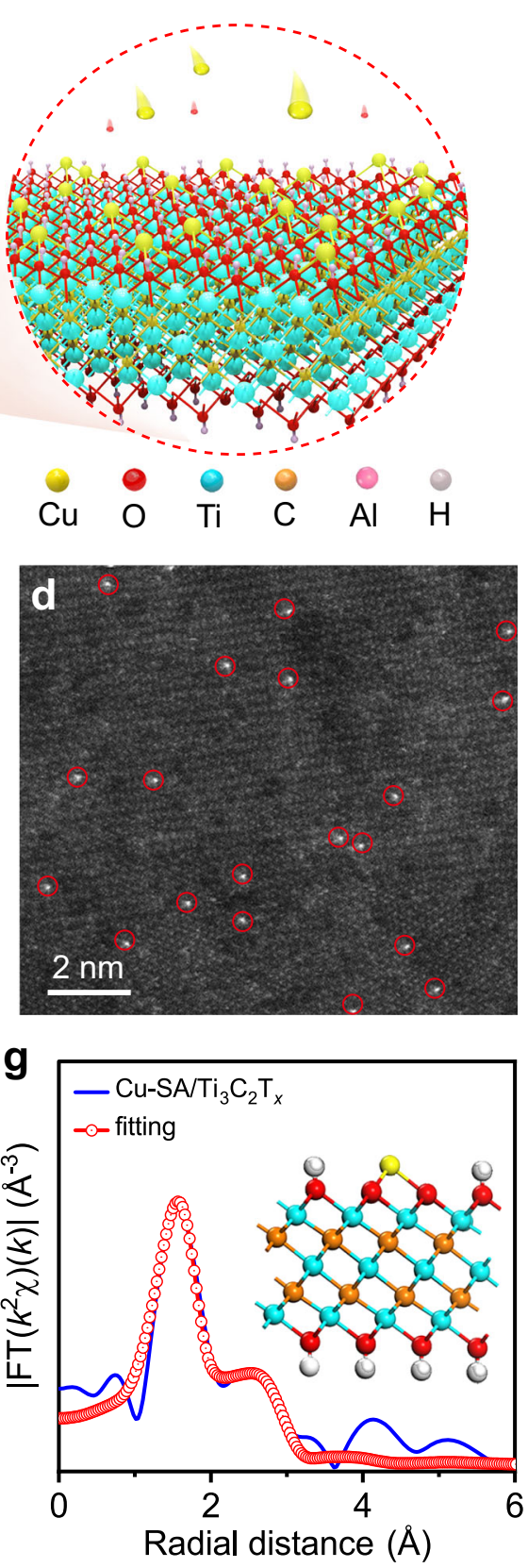

Fig. 1 Preparation and structural characterization of $\mathbf{C u}-\mathbf{S A} / \mathbf{T i}_{\mathbf{3}} \mathbf{C}_{\mathbf{2}} \mathbf{T}_{\mathbf{x}}$. a Schematic illustration of the synthesis procedure. $\mathbf{b} X R D$ pattern. $\mathbf{c} T E M$ image. d HAADF-STEM image in which some of the $\mathrm{Cu}$ SAs are highlighted by red circles. e XANES spectra at the $\mathrm{Cu} \mathrm{K}$-edge with $\mathrm{CuO}$, $\mathrm{Cu} \mathrm{H}_{2} \mathrm{O}$ and $\mathrm{Cu}$ foil as

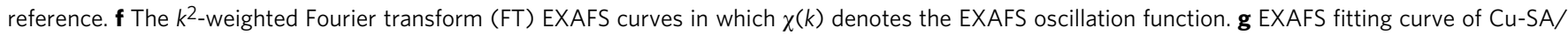
$\mathrm{Ti}_{3} \mathrm{C}_{2} \mathrm{~T}_{x}$, insert is an illustration of $\mathrm{Cu}-\mathrm{SA} / \mathrm{Ti}_{3} \mathrm{C}_{2} \mathrm{~T}_{x}$ structure. The yellow, blue, dark yellow, red and white balls represent $\mathrm{Cu}$, $\mathrm{Ti}$, $\mathrm{C}$, $\mathrm{O}$ and $\mathrm{H}$, respectively.

in $\mathrm{Cu}-\mathrm{SA} / \mathrm{Ti}_{3} \mathrm{C}_{2} \mathrm{~T}_{x}$ (inset of Fig. 1g). Moreover, the Bader charge analysis of the optimized model indicates that $\mathrm{Cu}$ SAs in $\mathrm{Cu}-\mathrm{SA} /$ $\mathrm{Ti}_{3} \mathrm{C}_{2} \mathrm{~T}_{x}$ are positively charged $(+0.42$, Supplementary Fig. 13$)$, in line with XANES result (Fig. 1e). Unfortunately, the CO diffuse reflectance infrared Fourier transform spectroscopy (CODRIFTS) measurement under ambient conditions failed to probe the dispersion of $\mathrm{Cu}$ in $\mathrm{Cu}-\mathrm{SA} / \mathrm{Ti}_{3} \mathrm{C}_{2} \mathrm{~T}_{x}$ (Supplementary Fig. 14), probably because of the weakening $\mathrm{CO}$ adsorption on the surface of $\mathrm{Cu}-\mathrm{SA} / \mathrm{Ti}_{3} \mathrm{C}_{2} \mathrm{~T}_{x}$ without an applied bias voltage. Since the oxygen atoms are part of $\mathrm{T}_{x}$ surface groups, this suggests that the $\mathrm{Cu}$ atoms are dispersed on the surface of the $\mathrm{Ti}_{3} \mathrm{C}_{2} \mathrm{~T}_{x}$ nanosheets.

COR performance of $\mathrm{Cu}-\mathrm{SA} / \mathrm{Ti}_{3} \mathrm{C}_{2} \mathrm{~T}_{x}$ in the alkaline system. $\mathrm{COR}$ properties of $\mathrm{Cu}-\mathrm{SA} / \mathrm{Ti}_{3} \mathrm{C}_{2} \mathrm{~T}_{x}$ were evaluated using a
Nafion-separated H-type cell with $\mathrm{CO}$-saturated $1 \mathrm{M} \mathrm{KOH}$ as electrolyte. The potentials were converted to the RHE scale. Linear sweep voltammetry (LSV; Fig. 2a) shows that the current densities (normalized by the geometrical surface area) increase with increasing applied potential. The current density of Cu-SA/ $\mathrm{Ti}_{3} \mathrm{C}_{2} \mathrm{~T}_{x}$ in CO-purged electrolyte is distinctly higher than that under Ar atmosphere, demonstrating good electrocatalytic activity toward the COR. Electrolysis was performed in a potential range of -0.4 to $-0.9 \mathrm{~V}$ vs RHE for $2 \mathrm{~h}$ at each constant potential. The gas and liquid products were quantified by gas chromatography (GC) and ${ }^{1} \mathrm{H}$ nuclear magnetic resonance (NMR) spectroscopy, respectively, in which dimethyl sulfoxide (DMSO) was used as an internal standard (Supplementary Fig. 15).

Figure $2 \mathrm{~b}$ shows the FEs of the reduction products as well as the competing hydrogen formation on $\mathrm{Cu}-\mathrm{SA} / \mathrm{Ti}_{3} \mathrm{C}_{2} \mathrm{~T}_{x}$ at the 

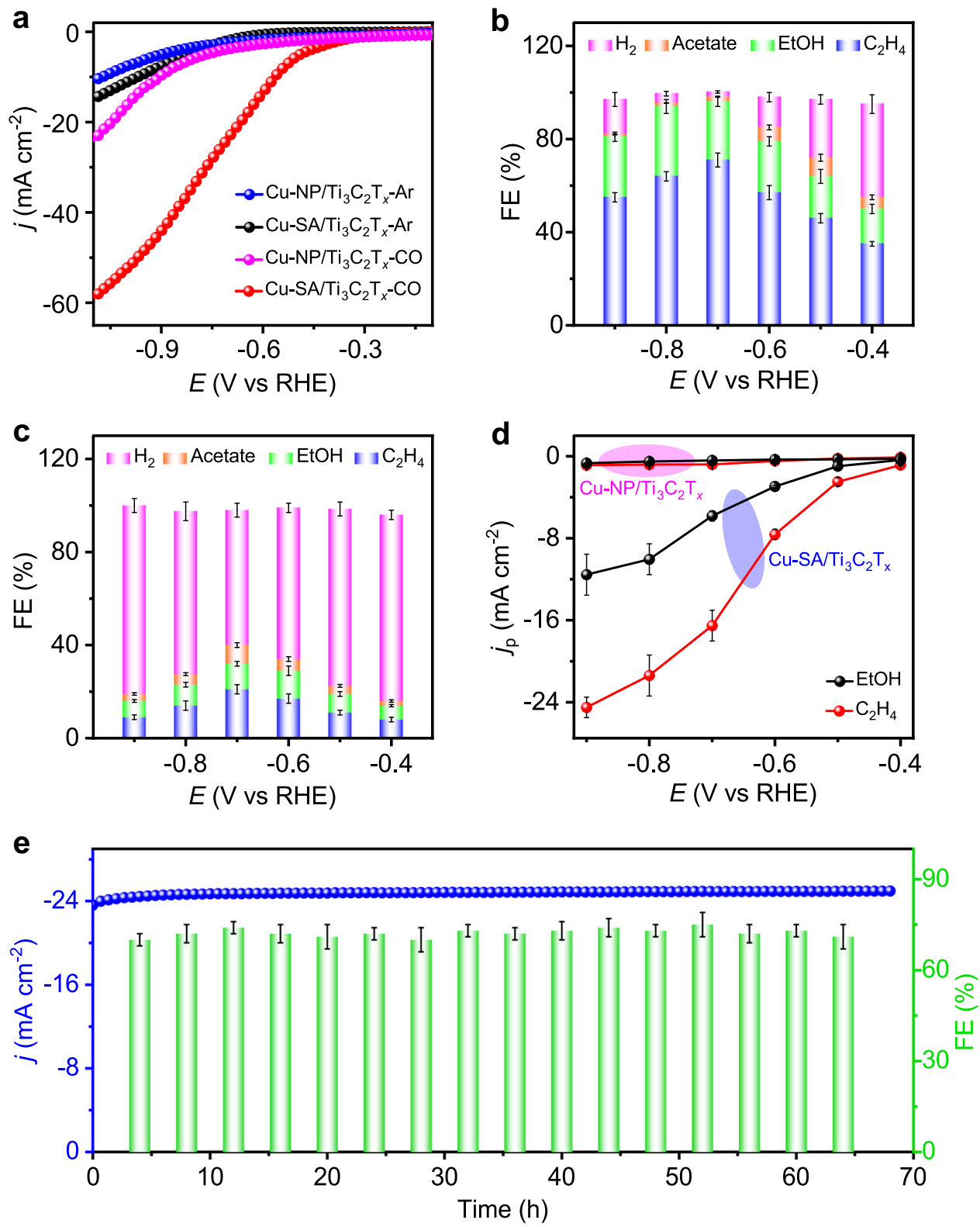

Fig. 2 Electrochemical $\mathbf{C O}$ reduction performances. a Linear sweep voltammetry curves of $\mathrm{Cu}-\mathrm{SA} / \mathrm{Ti}_{3} \mathrm{C}_{2} \mathrm{~T}_{x}$ measured in $\mathrm{CO}$ - or $\mathrm{Ar}$-saturated $1 \mathrm{M} \mathrm{KOH}$ solution at a scan rate of $10 \mathrm{mV} \mathrm{s}^{-1}$; potentials have been $i \mathrm{R}$-corrected. $\mathbf{b}$, c Faradaic efficiencies (FE) toward $\mathrm{H}_{2}$ and $\mathrm{CO}$ reduction products $\left(\mathrm{C}_{2} \mathrm{H}_{4}\right.$, EtOH, and acetate) of $\mathbf{b} \mathrm{Cu}-\mathrm{SA} / \mathrm{Ti}_{3} \mathrm{C}_{2} \mathrm{~T}_{x}$ and $\mathbf{c} \mathrm{Cu}-\mathrm{NP} / \mathrm{Ti}_{3} \mathrm{C}_{2} \mathrm{~T}_{x}$ at various applied potentials for $2 \mathrm{~h}$. $\mathbf{d}$ The partial current densities $\left(\mathrm{j}_{\mathrm{p}}\right)$ of $\mathrm{C}_{2} \mathrm{H}_{4}$ and EtOH at test potentials. e Chronoamperometry test and $\mathrm{FE}$ of $\mathrm{C}_{2} \mathrm{H}_{4}$ for $\mathrm{Cu}-\mathrm{SA} / \mathrm{Ti}_{3} \mathrm{C}_{2} \mathrm{~T}_{x}$ at an applied constant potential of $-0.7 \mathrm{~V}$ vs RHE for $68 \mathrm{~h}$. The error bars correspond to the standard deviations of measurements over three separately prepared samples under the same testing conditions.

applied potentials. A high total $\mathrm{FE}$ of $98 \%$ (-0.7 V vs RHE) for $\mathrm{C}_{2}$ products has been achieved, suggesting the effective suppression of the competing HER. This value is comparable with those of $\mathrm{Cu}$ nanoflowers $^{42}\left(\sim 100 \% \mathrm{FE}\right.$ for $\mathrm{C}_{2+}$ products) and $\mathrm{Cu}$ nanoparticles $^{9}$ ( $\sim 91 \%$ FE for $\mathrm{C}_{2+}$ products). In the wide potential range from -0.6 to $-0.9 \mathrm{~V}$ vs $\mathrm{RHE}, \mathrm{C}_{2}$ production reveals a total product selectivity of more than $79 \%$, which declined at more negative potentials due to mass transport limitations of $\mathrm{CO}^{5,43}$. $\mathrm{C}_{2} \mathrm{H}_{4}$ is exclusively produced as the gas product of $\mathrm{COR}$ for $\mathrm{Cu}$ $\mathrm{SA} / \mathrm{Ti}_{3} \mathrm{C}_{2} \mathrm{~T}_{x}$, obtaining a maximum $\mathrm{FE}$ of $71 \%$ at $-0.7 \mathrm{~V}$ vs $\mathrm{RHE}$, which is significantly larger than the highest value of $52.7 \%$ reported for $\mathrm{Cu} \mathrm{NPs}^{44}$ (Supplementary Table 2). Meantime, in the liquid product, the $\mathrm{FE}$ of $\mathrm{EtOH}$ for $\mathrm{Cu}-\mathrm{SA} / \mathrm{Ti}_{3} \mathrm{C}_{2} \mathrm{~T}_{x}$ reached the highest value of $30 \%$ at $-0.8 \mathrm{~V}$ vs RHE. At $-0.7 \mathrm{~V}$ vs RHE, the FEs of EtOH and acetate for $\mathrm{Cu}-\mathrm{SA} / \mathrm{Ti}_{3} \mathrm{C}_{2} \mathrm{~T}_{x}$ were 25.0 and $2.2 \%$, respectively, and the corresponding formation rates are 2.79 and $0.44 \mathrm{mM} \mathrm{h}^{-1}$, respectively (Supplementary Fig. 16). Furthermore, the partial current densities $\left(j_{\mathrm{p}}\right)$ of $\mathrm{C}_{2} \mathrm{H}_{4}$ and $\mathrm{EtOH}$ for $\mathrm{Cu}-\mathrm{SA} / \mathrm{Ti}_{3} \mathrm{C}_{2} \mathrm{~T}_{x}$ were as high as -16.5 and $-5.8 \mathrm{~mA} \mathrm{~cm}^{-2}$, respectively, at $-0.7 \mathrm{~V}$ vs RHE (Fig. 2d).

$\mathrm{Cu}-\mathrm{SA} / \mathrm{Ti}_{3} \mathrm{C}_{2} \mathrm{~T}_{x}$ shows good stability over $68 \mathrm{~h}$ electrolysis after the initial activation of the catalyst layer in the first $30 \mathrm{~min}$ (Fig. 2e). An average current density of $-24.8 \mathrm{~mA} \mathrm{~cm}^{-2}$ is observed over the time of the long-term electrolysis. The corresponding $\mathrm{FE}$ for $\mathrm{C}_{2} \mathrm{H}_{4}$ is larger than $70 \%$ along with a $\sim 3 \%$ oscillation caused by bubble accumulation and a sudden flush out ${ }^{12}$. HAADF-STEM images, as well as XRD and XPS results of $\mathrm{Cu}-\mathrm{SA} / \mathrm{Ti}_{3} \mathrm{C}_{2} \mathrm{~T}_{x}$ after electrochemical testing, indicate the well-preserved single $\mathrm{Cu}$ sites without the presence of any clusters and particles (Supplementary Figs. 17-19). Additional 
density-functional-theory (DFT) calculations further confirmed the high kinetic stability of $\mathrm{Cu}$ SAs during the electrolysis (Supplementary Figs. 20 and 21).

To confirm the origins of carbon in the COR products, isotopic labeling experiments were performed by using ${ }^{13} \mathrm{CO}$ as the feeding gas. The ${ }^{13} \mathrm{C}$-labeled reduction products were analyzed by a quadrupole-type mass spectrometer (MS). Dominant peaks of ${ }^{13} \mathrm{C}-\mathrm{C}_{2} \mathrm{H}_{4}(\mathrm{~m} / z=30),{ }^{13} \mathrm{C}-\mathrm{EtOH}(\mathrm{m} / z=47)$, and ${ }^{13} \mathrm{C}$-acetic acid $(m / z=62)$ were observed (Supplementary Figs. $22-24)^{45-47}$. The evidence confirms that the evolved reduction products derive from the $\mathrm{CO}$ electrolysis over $\mathrm{Cu}-\mathrm{SA} / \mathrm{Ti}_{3} \mathrm{C}_{2} \mathrm{~T}_{x}$. In addition, the generated $\mathrm{EtOH}$ can also be excluded from the residual $\mathrm{EtOH}$ in preparing the working electrode (Supplementary Fig. 25).

As a comparison, $\mathrm{Cu}$ particles $(10-50 \mathrm{~nm})$ supported on $\mathrm{Ti}_{3} \mathrm{C}_{2} \mathrm{~T}_{x}$ (denoted as $\mathrm{Cu}-\mathrm{NP} / \mathrm{Ti}_{3} \mathrm{C}_{2} \mathrm{~T}_{x}$; Supplementary Figs. 26-30) were also prepared with a $\mathrm{Cu}$ loading of $5.2 \mathrm{wt} \%$. Cu-NP/ $/ \mathrm{Ti}_{3} \mathrm{C}_{2} \mathrm{~T}_{x}$ shows a very low current density of $-16.2 \mathrm{~mA} \mathrm{~cm}^{-2}$ at $-1.0 \mathrm{~V}$ vs RHE (Fig. 2a), which is 3.2-fold lower than that on $\mathrm{Cu}-\mathrm{SA} /$ $\mathrm{Ti}_{3} \mathrm{C}_{2} \mathrm{~T}_{x}\left(-52.2 \mathrm{~mA} \mathrm{~cm}^{-2}\right)$. The highest FEs of $\mathrm{C}_{2} \mathrm{H}_{4}$ and $\mathrm{EtOH}$ were only $21 \%(-0.7 \mathrm{~V}$ vs RHE) and $12 \%$ ( $-0.6 \mathrm{~V}$ vs RHE), respectively, in the electrocatalytic process on $\mathrm{Cu}-\mathrm{NP} / \mathrm{Ti}_{3} \mathrm{C}_{2} \mathrm{~T}_{x}$ (Fig. 2c), which are about 3.4- and 2.1-fold lower than on Cu-SA/ $\mathrm{Ti}_{3} \mathrm{C}_{2} \mathrm{~T}_{x}$, respectively. In addition, the calculated formation rates of $\mathrm{EtOH}$ and acetate for $\mathrm{Cu}-\mathrm{NP} / \mathrm{Ti}_{3} \mathrm{C}_{2} \mathrm{~T}_{x}$ were 0.19 and $0.31 \mathrm{mM} \mathrm{h}^{-1}$ at $-0.7 \mathrm{~V}$ vs RHE, respectively (Supplementary Fig. 16). $\mathrm{H}_{2}$ production dominated the whole potential range, showing an FE of $59-81 \%$ (Fig. 2c). The influence of $\mathrm{Cu} \mathrm{NP}$ loading amount in $\mathrm{Cu}-\mathrm{NP} / \mathrm{Ti}_{3} \mathrm{C}_{2} \mathrm{~T}_{x}$ for the $\mathrm{COR}$ performance was also investigated. With an increase of $\mathrm{Cu}$ precursor in the synthetic process (Supplementary Figs. 30 and 31), ICP-OES results revealed that the $\mathrm{Cu}$ content in $\mathrm{Cu}-\mathrm{NP} / \mathrm{Ti}_{3} \mathrm{C}_{2} \mathrm{~T}_{x}$ increased from 5.2 to 9.8 and $20.3 \mathrm{wt} \%$, respectively. We found that the two additional $\mathrm{Cu}-\mathrm{NP} / \mathrm{Ti}_{3} \mathrm{C}_{2} \mathrm{~T}_{x}$ control samples showed relatively improved COR activities (Supplementary Fig. 32); however, their performances are still inferior to those of $\mathrm{Cu}-\mathrm{SA} / \mathrm{Ti}_{3} \mathrm{C}_{2} \mathrm{~T}_{x}$ (Fig. 2a, b), suggesting that the $\mathrm{Cu} N P$ content is not the major contribution to the COR activity.

Meanwhile, the other two samples of pristine $\mathrm{Ti}_{3} \mathrm{C}_{2} \mathrm{~T}_{x}$ (Supplementary Fig. 6) and reduced $\mathrm{Ti}_{3} \mathrm{C}_{2} \mathrm{~T}_{x}$ (namely R$\mathrm{Ti}_{3} \mathrm{C}_{2} \mathrm{~T}_{x}$, Supplementary Fig. 33) were prepared as comparation. As seen in Supplementary Figs. 34 and 35, the maximum FEs of $\mathrm{C}_{2} \mathrm{H}_{4}$ formation for $\mathrm{Ti}_{3} \mathrm{C}_{2} \mathrm{~T}_{x}$ and $\mathrm{R}-\mathrm{Ti}_{3} \mathrm{C}_{2} \mathrm{~T}_{x}$ were $7.5 \%(-0.8 \mathrm{~V}$ vs RHE) and $5.2 \%$ (-0.7 V vs RHE), respectively, both of them are significantly lower than that of $\mathrm{Cu}-\mathrm{SA} / \mathrm{Ti}_{3} \mathrm{C}_{2} \mathrm{~T}_{x}$. This finding demonstrates that the $\mathrm{Ti}_{3} \mathrm{C}_{2} \mathrm{~T}_{x}$ support helps to capture and stabilize $\mathrm{Cu}$ species and the impact on the selectivity of $\mathrm{COR}$ is negligible. The high performance of $\mathrm{Cu}-\mathrm{SA} / \mathrm{Ti}_{3} \mathrm{C}_{2} \mathrm{~T}_{x}$ comes from the atomically dispersed $\mathrm{Cu}$-related active sites.

To further confirm the activity of $\mathrm{Cu}$ SAs, the COR activity of $\mathrm{Cu}-\mathrm{SA} / \mathrm{Ti}_{3} \mathrm{C}_{2} \mathrm{~T}_{x}$ was examined in electrolyte containing $0.1 \mathrm{mM}$ $\mathrm{KSCN}$. SCN ${ }^{-}$anions are known to coordinate with $\mathrm{Cu}$ and poison the single $\mathrm{Cu}$ sites ${ }^{48,49}$. In the presence of $\mathrm{SCN}^{-}, \mathrm{Cu}-\mathrm{SA} / \mathrm{Ti}_{3} \mathrm{C}_{2} \mathrm{~T}_{x}$ exhibits a noticeable decay in current density (Supplementary Fig. 36). Meanwhile, the obtained highest $\mathrm{FE}_{\mathrm{C} 2}$ of $\mathrm{Cu}-\mathrm{SA} / \mathrm{Ti}_{3} \mathrm{C}_{2} \mathrm{~T}_{x}$ is as low as $26 \%(-0.7 \mathrm{~V}$ vs. $\mathrm{RHE})$, much smaller than that of electrolyte without $\mathrm{SCN}^{-}$(Fig. 2b). These results strongly demonstrate that $\mathrm{Cu}$ single atoms act as the COR sites.

The increased electrochemical active surface area (ECSA) and interfacial charge transfer rate (Supplementary Figs. 37 and 38) may be potentially accounted for the enhanced COR activity of $\mathrm{Cu}-\mathrm{SA} / \mathrm{Ti}_{3} \mathrm{C}_{2} \mathrm{~T}_{x}$. As shown in Supplementary Fig. 39, the ECSAcorrected LSV results depict a much better catalytic current density of $\mathrm{Cu}-\mathrm{SA} / \mathrm{Ti}_{3} \mathrm{C}_{2} \mathrm{~T}_{x}$ in comparison with $\mathrm{Cu}-\mathrm{NP} / \mathrm{Ti}_{3} \mathrm{C}_{2} \mathrm{~T}_{x}$, implying that the presence of $\mathrm{Cu}$ SAs resulted in higher intrinsic activity. According to a previous study ${ }^{42}$, the inferior COR performance of $\mathrm{Cu}-\mathrm{NP} / \mathrm{Ti}_{3} \mathrm{C}_{2} \mathrm{~T}_{x}$ might result from the smaller ECSA in comparison with $\mathrm{Cu}-\mathrm{SA} / \mathrm{Ti}_{3} \mathrm{C}_{2} \mathrm{~T}_{x}$, which make it favor the competitive hydrogen evolution.

Theoretical insights on COR activity. To elucidate the COR activity, the mechanistic regimes for the formation of $\mathrm{C}_{2} \mathrm{H}_{4}$ and $\mathrm{EtOH}$ on $\mathrm{Cu}-\mathrm{SA} / \mathrm{Ti}_{3} \mathrm{C}_{2} \mathrm{~T}_{x}$ catalyst was parsed by calculating key intermediates and favorable reaction pathways in each primitive reaction, as shown in Fig. 3a, c and Supplementary Fig. 40. Generally, the $\mathrm{Ti}_{3} \mathrm{C}_{2} \mathrm{~T}_{x}$ surface is functionalized with $\mathrm{T}_{x}$ groups, including $-\mathrm{O},-\mathrm{OH}$, and $-\mathrm{F}$. As revealed by the electron energy loss spectroscopy (EELS) spectrum in Supplementary Fig. 41, the residual $\mathrm{F}$ content in $\mathrm{Cu}-\mathrm{SA} / \mathrm{Ti}_{3} \mathrm{C}_{2} \mathrm{~T}_{x}$ is very low in comparison with $\mathrm{O}$. Moreover, the $-\mathrm{F}$ is thermodynamically unfavorable compared with $-\mathrm{O}$ and $-\mathrm{OH}$ moieties ${ }^{50}$. In addition, in an aqueous solution, the $-\mathrm{O}$ termination would become hydroxylated under the electrocatalysis according to the surface pourbaix diagrams ${ }^{51}$. Therefore, in this work, the $-\mathrm{OH}$ terminated Cu-SA/ $\mathrm{Ti}_{3} \mathrm{C}_{2} \mathrm{~T}_{x}$ model was employed, and the solvent effect is also considered using the implicit solvation model ${ }^{52}$. The primitive reaction on $\mathrm{Cu}$ (111) surface (Supplementary Fig. 27), which represents the predominate exposed active surface of $\mathrm{Cu}-\mathrm{NP} /$ $\mathrm{Ti}_{3} \mathrm{C}_{2} \mathrm{~T}_{x}$, was also computed as a comparison.

The overall total reaction processes of $\mathrm{C}_{2} \mathrm{H}_{4}$ and $\mathrm{EtOH}$ are indicated below in equations (1) and (2), both of them are formed in $8 \mathrm{e}^{-}$reductions with $\mathrm{H}_{2} \mathrm{O}$ as the $\mathrm{H}^{+}$source:

$$
\begin{gathered}
2 \mathrm{CO}+6 \mathrm{H}_{2} \mathrm{O}+8 \mathrm{e}^{-} \rightarrow \mathrm{C}_{2} \mathrm{H}_{4}+8 \mathrm{OH}^{-} \\
2 \mathrm{CO}+7 \mathrm{H}_{2} \mathrm{O}+8 \mathrm{e}^{-} \rightarrow \mathrm{C}_{2} \mathrm{H}_{5} \mathrm{OH}+8 \mathrm{OH}^{-}
\end{gathered}
$$

Since that the $2^{*} \mathrm{CO} \rightarrow{ }^{*} \mathrm{COCO}$ process failed to proceed on $\mathrm{Cu}-\mathrm{SA} / \mathrm{Ti}_{3} \mathrm{C}_{2} \mathrm{~T}_{x}$ due to the large $\mathrm{Cu}-\mathrm{Cu}$ distance in the catalyst (Supplementary Fig. 42), the ${ }^{*} \mathrm{CHO}$ pathway is considered for $\mathrm{Cu}-\mathrm{SA} / \mathrm{Ti}_{3} \mathrm{C}_{2} \mathrm{~T}_{x}$ (Fig. 3b). Firstly, one $\mathrm{CO}$ molecule adsorbed on the $\mathrm{Cu}$ SA site, resulting in the formation of ${ }^{*} \mathrm{CO}$ species $\left(*\right.$ denotes a binding site), and then ${ }^{*} \mathrm{CHO}$ formed by one proton transfer process. Next, ${ }^{*} \mathrm{CHO}$ was coupled with another $\mathrm{CO}$ by ${ }^{*} \mathrm{CHO}+\mathrm{CO} \rightarrow{ }^{*} \mathrm{CHO}-\mathrm{CO}$ (refs. ${ }^{53,54}$ ) with a free energy barrier of $0.32 \mathrm{eV}$, which is the rate-limiting step (RLS) during the whole COR process. For $\mathrm{Cu}$ (111), two $\mathrm{C}-\mathrm{C}$ coupling pathways were calculated. ${ }^{*} \mathrm{CO}$ can be first hydrogenated into ${ }^{*} \mathrm{COH}$ with a free energy barrier of $1.18 \mathrm{eV}$ (Supplementary Fig. 43), or two ${ }^{*} \mathrm{CO}$ coupled directly to from ${ }^{*} \mathrm{COCO}$ with a free energy barrier of $0.94 \mathrm{eV}$ (Fig. 3b and Supplementary Fig. 44) ${ }^{55,56}$. The large free energy for these two $\mathrm{C}-\mathrm{C}$ coupling step implies high-energy barriers for the CO-to- $\mathrm{C}_{2}$ process, consistent with experimentally observed COR performance (Fig. 2c). To further verify the activation energy of the RLS, the climbing image nudged elastic band (CI-NEB) method was employed to calculate the transition states. As shown in Supplementary Fig. 45, the activation barrier for ${ }^{*} \mathrm{CHO}-\mathrm{CO}$ formation on $\mathrm{Cu}-\mathrm{SA} / \mathrm{Ti}_{3} \mathrm{C}_{2} \mathrm{~T}_{x}$ is as low as $0.82 \mathrm{eV}$, which is much lower than that of the $\mathrm{C}-\mathrm{C}$ coupling step on $\mathrm{Cu}$ (111) surface $(1.36 \mathrm{eV})$. Therefore, this lower energy demand in the RLS of $\mathrm{Cu}-\mathrm{SA} / \mathrm{Ti}_{3} \mathrm{C}_{2} \mathrm{~T}_{x}$ accounts for its outstanding COR performance. In addition, the COR pathway was also calculated on pure $\mathrm{Ti}_{3} \mathrm{C}_{2} \mathrm{~T}_{x}$ as shown in Supplementary Fig. 46. It indicated that a large energy barrier of $1.29 \mathrm{eV}$ is required for the activation of $\mathrm{CO}$ on $\mathrm{Ti}_{3} \mathrm{C}_{2} \mathrm{~T}_{x}$, much higher than that on $\mathrm{Cu}-\mathrm{SA} / \mathrm{Ti}_{3} \mathrm{C}_{2} \mathrm{~T}_{x}$. This agrees well with the poor COR performance of $\mathrm{Ti}_{3} \mathrm{C}_{2} \mathrm{~T}_{x}$ as discussed above.

The production selectivity of the COR reaction of $\mathrm{Cu}-\mathrm{SA} /$ $\mathrm{Ti}_{3} \mathrm{C}_{2} \mathrm{~T}_{x}$ was then discussed. Overall, the reaction pathways to $\mathrm{C}_{2} \mathrm{H}_{4}$ and $\mathrm{EtOH}$ were identical in their beginning $4 \mathrm{e}^{-}$transfer process ${ }^{57,58}$, which initially resulted in the formation of the ${ }^{*} \mathrm{C}-\mathrm{CHOH}$. After that, the proton-electron transfer of ${ }^{*} \mathrm{C}-\mathrm{CHOH}$ 

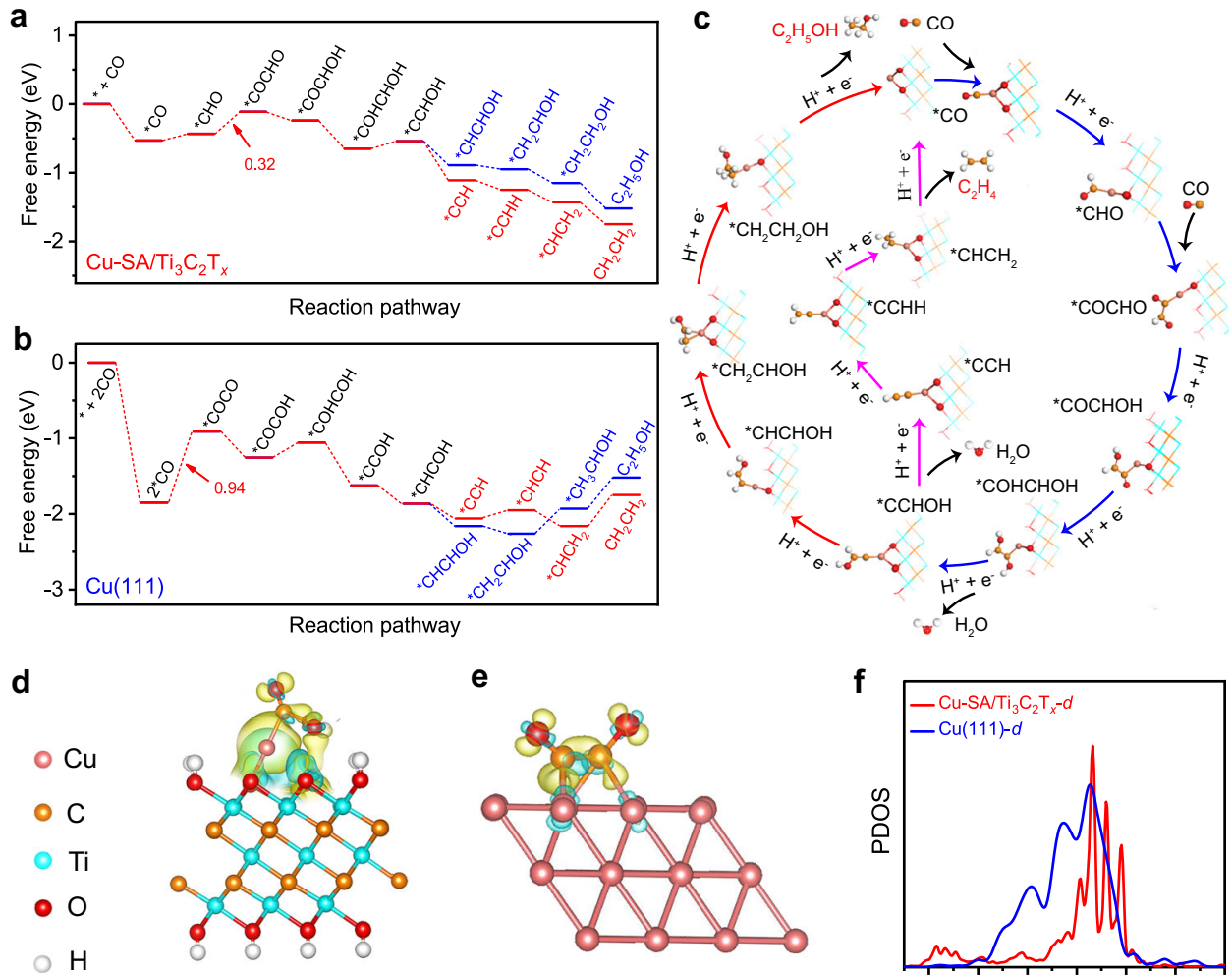

$\mathbf{e}$
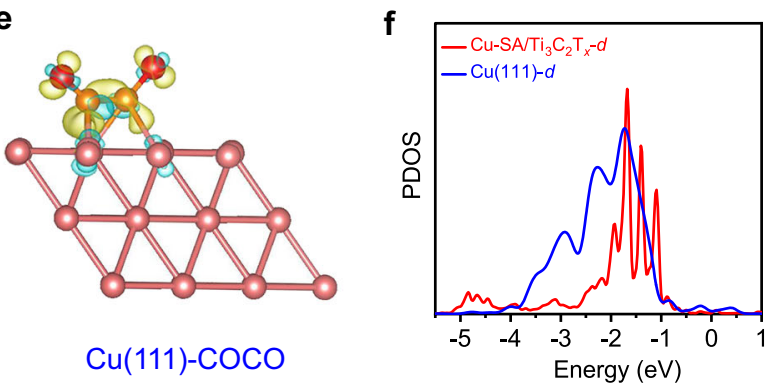

Fig. 3 The optimized energy pathway for $\mathbf{C O}$ reduction toward $\mathbf{C}_{\mathbf{2}} \mathbf{H}_{\mathbf{4}}$ and EtOH on $\mathbf{C u}-\mathbf{S A} / \mathrm{Ti}_{3} \mathbf{C}_{\mathbf{2}} \mathbf{T}_{\boldsymbol{x}} \mathbf{a}, \mathbf{b}$ Free energy diagrams of $\mathrm{CO}$ reduction over a Cu$\mathrm{SA} / \mathrm{Ti}_{3} \mathrm{C}_{2} \mathrm{~T}_{x}$ and $\mathbf{b} \mathrm{Cu}$ (111). The reason for choosing $\mathrm{Cu}$ (111) is that Supplementary Fig. 27 indicates the preferential orientation of the $\mathrm{Cu}$ nanoparticles in $\mathrm{Cu}-\mathrm{NP} / \mathrm{Ti}_{3} \mathrm{C}_{2} \mathrm{~T}_{x}$ is $\langle 111\rangle$. c Schematic representation of $\mathrm{CO}$ reduction reaction pathways. In some adsorption configurations, $\mathrm{Cu}-\mathrm{O}$ bond was elongated to get the lowest energy state. $\mathbf{d}$, e Charge density difference of the ${ }^{*} \mathrm{COCHO}$-adsorbed and ${ }^{*} \mathrm{COCO}$-adsorbed configuration in $\mathbf{d} \mathrm{Cu}-\mathrm{SA} / \mathrm{Ti}_{3} \mathrm{C}_{2} \mathrm{~T}_{x}$ and e $\mathrm{Cu}$ (111), respectively. $\mathbf{f}$ The projected densities of states (PDOS) of $d$-orbitals in $\mathrm{Cu}-\mathrm{SA}_{\mathrm{ST}} \mathrm{T}_{3} \mathrm{C}_{2} \mathrm{~T}_{x}$ and $\mathrm{Cu}$ (111) with an aligned Fermi level. Yellow and blue shadows represent charge accumulation and depletion in the space, respectively; the pinkish-orange, blue, dark yellow, red, and white spheres represent $\mathrm{Cu}, \mathrm{Ti}, \mathrm{C}, \mathrm{O}$, and $\mathrm{H}$, respectively.

splits the pathway to $\mathrm{C}_{2} \mathrm{H}_{4}$ from the pathway to EtOH. The free energy drop of the ${ }^{*} \mathrm{C}-\mathrm{CHOH} \rightarrow{ }^{*} \mathrm{C}-\mathrm{CH}(-0.62 \mathrm{eV})$ toward the formation of $\mathrm{C}_{2} \mathrm{H}_{4}$ is greater than that of the analog and competitive step ${ }^{*} \mathrm{C}-\mathrm{CHOH} \rightarrow{ }^{*} \mathrm{CH}-\mathrm{CHOH}(-0.45 \mathrm{eV})$ in the $\mathrm{EtOH}$ formation pathway, suggesting a higher selectivity toward $\mathrm{C}_{2} \mathrm{H}_{4}$ formation. This may be caused by the greater $\mathrm{C}-\mathrm{C} \pi$ bond unsaturation of ${ }^{*} \mathrm{C}-\mathrm{CH}$ compared with ${ }^{*} \mathrm{CH}-\mathrm{CHOH}$, which leads to a more stable absorption on the surface of catalysts ${ }^{56,59}$. Similar results can also be observed in $\mathrm{CO}_{2} \mathrm{R}$ process, generally, the production of $\mathrm{C}_{2} \mathrm{H}_{4}$ was higher than $\mathrm{EtOH}$ (refs. ${ }^{59-61}$ ).

Moreover, charge accumulation and depletion between $\mathrm{C}$ and $\mathrm{Cu}$ atoms are observed on the charge density difference maps of both $\mathrm{Cu}-\mathrm{SA} / \mathrm{Ti}_{3} \mathrm{C}_{2} \mathrm{~T}_{x}$ and $\mathrm{Cu}$ (111) surfaces (Fig. 3d, e), which is an indicator for successful adsorption of key intermediates on the catalyst surfaces. To further elucidate the electronic structures, we compared the projected densities of states (PDOS) of the $d$-orbitals of $\mathrm{Cu}-\mathrm{SA} / \mathrm{Ti}_{3} \mathrm{C}_{2} \mathrm{~T}_{x}$ and $\mathrm{Cu}$ (111). It is found that the peak of the $d$ orbital of $\mathrm{Cu}-\mathrm{SA} / \mathrm{Ti}_{3} \mathrm{C}_{2} \mathrm{~T}_{x}$ is narrower than that of $\mathrm{Cu}(111)$ and shifts toward the Fermi level, demonstrating promoted electron transport, and thus, higher reactivity (Fig. $3 \mathrm{f})^{62,63}$. In addition, the ideal selectivity of $\mathrm{Cu}-\mathrm{SA} / \mathrm{Ti}_{3} \mathrm{C}_{2} \mathrm{~T}_{x}$ toward $\mathrm{C}_{2} \mathrm{H}_{4}$ and EtOH formation can also be attributed to the uniform catalytic sites resulting from the certain and simple structure, suppressing the formation of key intermediates toward diverse products (Supplementary Fig. 40). In contrast, the high selectivity nature for conventional catalysts is typically difficult to possess due to their diverse and complicated active sites. These theoretical calculation results provide some mechanistic explanations for the good activity of $\mathrm{Cu}-\mathrm{SA} / \mathrm{Ti}_{3} \mathrm{C}_{2} \mathrm{~T}_{x}$.

Additional DFT calculations were performed to determine the free energy $\left(\Delta G_{\mathrm{H}^{*}}\right)$ of $\mathrm{H}$ adsorption on the catalyst surface, which has been identified as a descriptor of $\mathrm{HER}$, as shown in Supplementary Fig. 47. It shows that the $\Delta G_{\mathrm{H}^{*}}$ of $\mathrm{Cu}-\mathrm{SA} / \mathrm{Ti}_{3} \mathrm{C}_{2} \mathrm{~T}_{x}$ is $-0.35 \mathrm{eV}$, much more negative than that on the $\mathrm{Cu}-\mathrm{NP} / \mathrm{Ti}_{3} \mathrm{C}_{2} \mathrm{~T}_{x}$ $(+0.18 \mathrm{eV})$. Accordingly, the proceeding of the HER process on the $\mathrm{Cu}-\mathrm{SA} / \mathrm{Ti}_{3} \mathrm{C}_{2} \mathrm{~T}_{x}$ surface is more difficult than on the $\mathrm{Cu}-\mathrm{NP} /$ $\mathrm{Ti}_{3} \mathrm{C}_{2} \mathrm{~T}_{x}$, agrees well with the experimental results in Fig. $2 \mathrm{~b}, \mathrm{c}$.

In summary, $\mathrm{Cu}$ SAs were successfully anchored to $\mathrm{Ti}_{3} \mathrm{C}_{2} \mathrm{~T}_{x}$ nanosheets $\left(\mathrm{Cu}-\mathrm{SA} / \mathrm{Ti}_{3} \mathrm{C}_{2} \mathrm{~T}_{x}\right)$ and firstly used as catalysts for the COR. Cu-SA/ $/ \mathrm{Ti}_{3} \mathrm{C}_{2} \mathrm{~T}_{x}$ exhibits an ultrahigh selectivity of $98 \%$ for the formation of $\mathrm{C}_{2}$ products and unprecedented selectivity for $\mathrm{C}_{2} \mathrm{H}_{4}$ production (71\%). Experiment and theoretical calculations revealed that the $\mathrm{O}$-coordinated $\mathrm{Cu}$ SAs are stable during the electrolysis. For COR, it can promote the formation of the key ${ }^{*} \mathrm{CO}-\mathrm{CHO}$ intermediate, and collectively decrease the free energy barrier of the rate-determining step. Overall, we speculate that the good selectivity of $\mathrm{Cu}-\mathrm{SA} / \mathrm{Ti}_{3} \mathrm{C}_{2} \mathrm{~T}_{x}$ toward the formation of $\mathrm{C}_{2} \mathrm{H}_{4}$ and $\mathrm{EtOH}$ can be attributed to its good reactivity and structural simplicity. Our work sheds new light on the design of more advanced SA electrodes for efficient energy conversion. Furthermore, the electrosynthesis of $\mathrm{C}_{2} \mathrm{H}_{4}$ and $\mathrm{EtOH}$ enabled by the presented catalysis could provide a highly selective and energetically efficient route to value-added chemicals and fuels using abundant industrial CO as starting material. 


\section{Methods}

Synthesis of $\mathrm{Ti}_{3} \mathbf{C}_{\mathbf{2}} \mathbf{T}_{\mathbf{x}}$. Typically, $1 \mathrm{~g}$ of $\mathrm{Ti}_{3} \mathrm{AlC}_{2}$ powder was mixed with $1 \mathrm{~g}$ of $\mathrm{LiF}$ and $10 \mathrm{~mL}$ of $\mathrm{HCl}$, and the obtained mixture was kept stirring for $24 \mathrm{~h}$ at $35^{\circ} \mathrm{C}$. The resulting solid residue was washed several times with deionized water and centrifuged at a speed of $1150 \times g$. Finally, $\mathrm{Ti}_{3} \mathrm{C}_{2} \mathrm{~T}_{x}$ was obtained by freeze-drying.

Synthesis of $\mathrm{NaBH}_{\mathbf{4}}$ reduced $\mathrm{Ti}_{3} \mathbf{C}_{\mathbf{2}} \mathbf{T}_{\mathbf{x}}\left(\mathbf{R}-\mathrm{Ti}_{3} \mathbf{C}_{\mathbf{2}} \mathbf{T}_{\mathbf{x}}\right)$. For the synthesis of R$\mathrm{Ti}_{3} \mathrm{C}_{2} \mathrm{~T}_{x}, 50 \mathrm{~mL}$ of $\mathrm{Ti}_{3} \mathrm{C}_{2} \mathrm{~T}_{x}$ suspension $\left(1 \mathrm{mg} \mathrm{mL}^{-1}\right)$ was mixed with $1 \mathrm{~mL}$ of $\mathrm{NaBH}_{4}$ aqueous solution $\left(10 \mathrm{mg} \mathrm{mL}^{-1}\right)$ and stirred for $30 \mathrm{~min}$. Subsequently, the mixture was ultrasonicated for $1 \mathrm{~h}$, and the $\mathrm{R}-\mathrm{Ti}_{3} \mathrm{C}_{2} \mathrm{~T}_{x}$ was obtained by centrifugation and freeze-drying.

Synthesis of Cu-SA/Ti ${ }_{3} \mathrm{C}_{2} \mathbf{T}_{\mathbf{x}}$ and $\mathrm{Cu}-\mathrm{NC} / \mathrm{Ti}_{3} \mathrm{C}_{\mathbf{2}} \mathbf{T}_{\boldsymbol{x}}$. In a typical synthesis procedure of $\mathrm{Cu}-\mathrm{SA} / \mathrm{Ti}_{3} \mathrm{C}_{2} \mathrm{~T}_{x}, 50 \mathrm{mg}$ of $\mathrm{Ti}_{3} \mathrm{C}_{2} \mathrm{~T}_{x}$ was firstly dissolved in $50 \mathrm{~mL}$ of water in a round-bottom flask, after that, the mixture was sonicated for $30 \mathrm{~min}$ to obtain a uniform dispersion. Then, a certain amount of $1 \mathrm{mg} \mathrm{mL}^{-1} \mathrm{CuCl}_{2} \cdot 2 \mathrm{H}_{2} \mathrm{O}(0.67 \mathrm{~mL}$ for $\mathrm{Cu}-\mathrm{SA} / \mathrm{Ti}_{3} \mathrm{C}_{2} \mathrm{~T}_{x}$ and $2.01 \mathrm{~mL}$ for $\mathrm{Cu}-\mathrm{NC} / \mathrm{Ti}_{3} \mathrm{C}_{2} \mathrm{~T}_{x}$ ) was added into $25 \mathrm{~mL}$ of $\mathrm{Ti}_{3} \mathrm{C}_{2} \mathrm{~T}_{x}$ suspension slowly, and electromagnetic stirred for $30 \mathrm{~min}$. Subsequently, the mixture was ultrasonicated for $1 \mathrm{~h}$. After centrifuged and washed with deionized water, the solid residue was vacuum freeze-dried to obtain $\mathrm{Cu}-\mathrm{SA} / \mathrm{Ti}_{3} \mathrm{C}_{2} \mathrm{~T}_{x}$.

Synthesis of Cu-NP/Ti ${ }_{3} \mathbf{C}_{2} \mathbf{T}_{\mathbf{x}}$. For the synthesis of $\mathrm{Cu}-\mathrm{NP} / \mathrm{Ti}_{3} \mathrm{C}_{2} \mathrm{~T}_{x}$ samples, $50 \mathrm{mg}$ of $\mathrm{Ti}_{3} \mathrm{C}_{2} \mathrm{~T}_{x}$ was first dissolving in $50 \mathrm{~mL}$ of deionized water, and then a certain amount of $1 \mathrm{mg} \mathrm{ml}^{-1} \mathrm{CuCl}_{2} \cdot 2 \mathrm{H}_{2} \mathrm{O}$ aqueous solution $(6.7,13.4$ or $26.8 \mathrm{~mL}$ ) was added into the above $\mathrm{Ti}_{3} \mathrm{C}_{2} \mathrm{~T}_{x}$ suspension slowly, followed by stirring for $30 \mathrm{~min}$. Then, $1 \mathrm{~mL}$ of hydrazine hydrate $\left(\mathrm{N}_{2} \mathrm{H}_{4} \cdot \mathrm{H}_{2} \mathrm{O}\right)$ was added into the above resultant mixture quickly, with vigorous stirring for $2 \mathrm{~h}$ at room temperature. Subsequently, the resulting solution was centrifuged, and the obtained residue was washed by deionized water. Finally, $\mathrm{Cu}-\mathrm{NP} / \mathrm{Ti}_{3} \mathrm{C}_{2} \mathrm{~T}_{x}-\mathrm{x}$ was obtained by freeze-drying. The $\mathrm{Cu}$ content in the three samples was determined by ICP-OES measurements as 5.2, 9.8, and $20.3 \mathrm{wt} \%$, respectively.

Materials characterizations. TEM and EDX mappings were performed using FEI Talos F200X instruments. Atomic-resolution HAADF-STEM images and EELS were taken using a Titan Themis 60-300 STEM equipment equipped with a spherical probe aberration corrector. XRD was performed on an X-ray diffractometer (Rigaku SmartLab $9 \mathrm{~kW})$ with $\mathrm{Cu} \mathrm{K} \alpha$ radiation $(\lambda=0.154598 \mathrm{~nm})$ at a scan rate of $10^{\circ} \mathrm{min}^{-1}$ from $3^{\circ}$ to $70^{\circ}$. XPS characterizations were conducted by Thermo Scientific Al Ka XPS system (ESCALAB250Xi), and the binding energies were calibrated by setting the measured binding energy of $\mathrm{C} 1 s$ to $284.8 \mathrm{eV}$. ICPOES analysis was conducted on a Thermo iCAP RQ instrument. The elemental analysis was performed by an elemental analyzer (Vario EL cube). CO-DRIFTS measurements were carried out on a Thermo Scientific Nicolet 6700 Fourier transform infrared (FT-IR) spectrometer.

XAFS measurements and analysis details. The $\mathrm{Cu}$ K-edge X-ray absorption spectra were collected on the unfocussed 20-pole $2 \mathrm{~T}$ wiggler side-station beamline 7-3 at the Stanford Synchrotron Radiation Lightsource under standard ring conditions of $3 \mathrm{GeV}$ and $\sim 500 \mathrm{~mA}$. The $\mathrm{Si}$ (220) double crystal monochromators were used for energy selection. The components from higher harmonics were diminished after detuning the monochromator by $30-40 \%$. By using cellulose as a binder and diluent, the solid samples were pressed into palettes and installed on a cryogenic sample rod. During data collection, they were kept inside a liquid helium CryoIndustries cryocooler at $\sim 10 \mathrm{~K}$. A detector of Lytle or Canberra Germanium 30-element array was used, and all the EXAFS data were measured to $k=15 \AA^{-1}$ in fluorescence mode. Internal energy was calibrated by simultaneous measurement of the absorption edge of a Cu-foil standard sample which is placed between two ionization chambers situated after the sample probe. The SamView of the Sixpack software was used to process the XAS data obtained from the Germanium detector. The normalization of data was accomplished by subtracting the cubic spline using the Athena program, in which the edge jump was assigned to 1.0. The FT-EXAFS data fitting was completed by the Artemis software. The structural parameters of bond distance $(R)$, coordination numbers $(N)$, and the bond variance $\left(\sigma^{2}\right.$, related to the Debye-Waller factor and the static disorders of the scattering atoms) were varied during the fitting process.

Electrochemical COR. Electrocatalytic properties of the catalysts were conducted using an electrochemistry workstation (CHI660D Shanghai Chenhua Instrument Co.) with an H-type electrochemical cell. The catholyte and anolyte compartments were separated using a Nafion-117 membrane to avoid possible diffusion. A graphite rod and a $\mathrm{Hg} / \mathrm{HgO}$ electrode were used as the counter and reference electrodes, respectively. The electrolyte used for all COR experiments was $1 \mathrm{M} \mathrm{KOH}$. A carbon paper loaded with samples was used as the working electrode. Typically, 6 $\mathrm{mg}$ of catalyst and $0.5 \mathrm{~mL}$ of Nafion solution $(0.05 \mathrm{wt} \%)$ were dispersed into $0.5 \mathrm{~mL}$ of EtOH (or isopropanol) by sonication for $30 \mathrm{~min}$. After that, the ink was dropped onto the carbon paper and dried naturally.

For the detection of the COR products, the electrolysis was carried out in fresh $\mathrm{CO}$-saturated $1 \mathrm{M} \mathrm{KOH}$ aqueous solution for $2 \mathrm{~h}$ at each applied potential. During the electrolysis, $\mathrm{CO}$ was continuously delivered into the cathodic compartment at a constant rate of $20 \mathrm{sccm}$. Polarization curves were recorded by a scan rate of $10 \mathrm{mV} \mathrm{s}^{-1}$. The long-term durability was examined by using a chronoamperometry method.

The cell outlet gas products were analyzed by a gas chromatograph (GC, 7890 Agilent) equipped with a PoraPLOT Q column and a molecular sieve column. A flame ionization detector (FID) and a thermal conductivity detector (TCD) were used to analyze the products.

The Faradaic efficiency of gas species $\left(\mathrm{FE}_{\text {gas }}\right)$ was calculated as follows:

$$
\mathrm{FE}_{\text {gas }}(\%)=\frac{N_{k} \times C_{k} \times V_{\mathrm{CO}} \times t \times \mathrm{F} \times 10^{-3}}{22.4 \mathrm{Q}}
$$

where $N_{k}$ is the exchanged electron numbers to produce species $k, C_{k}$ is the concentration of the product, measured by GC; $V_{\mathrm{CO}}$ is the $\mathrm{CO}$ flow rate; $t$ is electrolysis time; F is the Faradaic constant $\left(96485 \mathrm{C} \mathrm{mol}^{-1}\right)$; $Q$ is the total charge amount.

The liquid products were analyzed using a ${ }^{1} \mathrm{H}$ NMR spectrum tested on a NMR (Bruker AVANCE AV III 400) equipment with a sensitivity of 480: 1 . Standard curves were first made using standard chemicals over the concentration range of interest (EtOH and acetate), with the internal standard DMSO in $1 \mathrm{M} \mathrm{KOH}^{60}$. The ${ }^{1} \mathrm{H}$ NMR spectrum was measured with water suppression via a presaturation method. The linearity of the two standard curves is as high as 0.999 (Supplementary Fig. 15), indicative of good accuracy in determining the concentration of products. In this work, the detection limits of EtOH and acetate were 0.1 and $0.15 \mu \mathrm{g} \mathrm{mL}^{-1}$, respectively. To quantify the liquid products, $0.5 \mathrm{~mL}$ fresh electrolyte electrolyzed at a determined potential for $2 \mathrm{~h}$ was mixed with $0.1 \mathrm{~mL} \mathrm{D}_{2} \mathrm{O}$ and $0.05 \mu \mathrm{L}$ DMSO. The ratio of the peak areas of the obtained EtOH and acetate to the DMSO peak area were compared to standard curves to quantify the concentrations of the reaction products. Then, the values of the EtOH or acetate yield rate can be derived from the slopes of the curves made by plotting the $\mathrm{EtOH}$ or acetate concentrations vs reaction times.

The Faradaic efficiency of liquid products $\left(\mathrm{FE}_{\text {liquid }}\right)$ was calculated as follows:

$$
\mathrm{FE}_{\text {Liquid }}(\%)=\frac{n \times V \times \mathrm{F} \times N_{k}}{Q}
$$

where $n$ (mol) is the content of EtOH or acetate, based on the calibration of the NMR; $V$ is the electrolyte volume in the cathodic chamber; $\mathrm{F}$ is the Faradaic constant $\left(=96485 \mathrm{C} \mathrm{mol}^{-1}\right) ; N_{k}$ is the number of transferred to produce species $k$; $Q$ is the total charge amount at different applied potentials.

For the isotope-labeling experiment, the same COR electrolysis was performed except ${ }^{13} \mathrm{CO}\left({ }^{13} \mathrm{C} 99.99 \%\right.$, Sigma-Aldrich) was used as the feeding gas. The products containing C-isotope was determined by a gas chromatograph (GC) equipped with an Agilent 5977A mass selective (MS) detector. High-purity $\mathrm{He}$ $(99.99 \%)$ was used as the carrier gas.

Computational details. All the DFT calculations were performed using the VASP package with VASPKIT code for post-processing the calculated data. Generalized gradient approximation (GGA) with the Perdew-Burke-Ernzerhof (PBE) functional is employed to treat the exchange-correlation energy. The interaction between core and valence electrons was described by the projected augmented wave (PAW) basis set. A converged cutoff was set to $500 \mathrm{eV}$. Only the electrons in brackets of $\mathrm{Ti}$ $\left[3 d^{2} 4 s^{2}\right], \mathrm{Cu}\left[3 d^{10} 4 s^{1}\right], \mathrm{C}\left[2 s^{2} 2 p^{2}\right], \mathrm{O}\left[2 s^{2} 2 p^{4}\right]$, and $\mathrm{H}\left[1 s^{1}\right]$ were treated as valence electrons. Implicit solvation corrections were applied, and the electrolyte was incorporated using the Poisson-Boltzmann model implemented in VASPsol ${ }^{52}$, in which the relative permittivity of the media $\epsilon_{\mathrm{r}}$ was chosen as 78.4. Zero damping DFT-D3 method was used to investigate weak intermolecular interactions. In geometry optimizations, the force convergence standard was set below $0.02 \mathrm{eV}^{-1}$. The $3 \times 3 \times 1$ Monkhorst-Pack $k$-point mesh was used for each $\mathrm{Cu}-\mathrm{SA} / \mathrm{Ti}_{3} \mathrm{C}_{2} \mathrm{~T}_{x}$ and $\mathrm{Cu}(111)$ slab optimization. To obtain electronic energy in the ground state accurately, $5 \times 5 \times 1$ grid was used to produce a self-consistent field. The bottom two layers were fixed to implement the free energy calculation of each intermediate. A $15 \AA$ vacuum layer was constructed along the $z$-axis for each model. Contributions of zero-point energies (ZPE), enthalpy, entropy, and $\mathrm{pH}$ to the free energies were considered and calculated. The calculation details of the Gibbs free energy change $(\Delta G)$ were expressed as follows:

$$
\Delta G=\Delta E+\Delta E_{\mathrm{ZPE}}+\int C_{p} d T-T \Delta S+\Delta G_{\mathrm{pH}}
$$

where $\Delta E$ is the electronic energy difference between the free-standing and the adsorption states of the intermediates; $\int C_{p} d T$ is the enthalpic temperature correction (see details in Supplementary Tables 3 and 4 ). $\Delta E_{\mathrm{ZPE}}$ and $\Delta S$ are the corrections of zero-point energy and variation of entropy, respectively (see details in Supplementary Tables 3 and 4). Frequencies $<50 \mathrm{~cm}^{-1}$ were set to $50 \mathrm{~cm}^{-1} . \Delta G_{\mathrm{pH}}$ is the free energy correction of $\mathrm{pH}$ and is calculated according to the equation below:

$$
\Delta G_{\mathrm{pH}}=k_{B} T \times \mathrm{pH} \times \ln 10
$$

where $k_{\mathrm{B}}$ is the Boltzmann constant. $\mathrm{pH}$ is set to 14 in this work. 
The binding energy of $\mathrm{Cu} \mathrm{SA}\left(E_{\mathrm{Cu}-\mathrm{SA} / \mathrm{Ti}_{3} \mathrm{C}_{2} \mathrm{~T}_{\mathrm{x}}}^{\mathrm{bin}}\right)$ and the cohesive energy of $\mathrm{Cu}$ bulk $\left(E_{\mathrm{Cu}_{\text {bulk }}}^{\mathrm{coh}}\right)$ were calculated by the following equations:

$$
\begin{gathered}
E_{\mathrm{Cu}-\mathrm{SA} / \mathrm{Ti}_{3} \mathrm{C}_{2} \mathrm{~T}_{x}}^{\mathrm{bind}}=-\left(E_{\mathrm{Cu}-\mathrm{SA} / \mathrm{Ti}_{3} \mathrm{C}_{2} \mathrm{~T}_{x}}-E_{\mathrm{Ti}_{3} \mathrm{C}_{2} \mathrm{~T}_{x}}-E_{\mathrm{Cu}-\mathrm{SA}}\right) \\
E_{\mathrm{Cu}_{\text {bulk }}}^{\text {coh }}=-\frac{E_{\mathrm{Cu}_{\text {bulk }}}-n E_{\mathrm{Cu}-\mathrm{SA}}}{n}
\end{gathered}
$$

where $E_{\mathrm{Cu}-\mathrm{SA}}, E_{\mathrm{Cu}_{\mathrm{bulu}_{\mathrm{u}}}}, E_{\mathrm{Ti}_{3} \mathrm{C}_{2} \mathrm{~T}_{x}}$ and $E_{\mathrm{Cu}-\mathrm{SA} / \mathrm{Ti}_{3} \mathrm{C}_{2} \mathrm{~T}_{x}}$ are the energies of a free single $\mathrm{Cu}$ atom, the $\mathrm{Cu}$ foil, the $\mathrm{Ti}_{3} \mathrm{C}_{2} \mathrm{~T}_{x}$ substrate slab, and $\mathrm{Cu}-\mathrm{SA} / \mathrm{Ti}_{3} \mathrm{C}_{2} \mathrm{~T}_{x}$ model, respectively; $n$ is the sum of $\mathrm{Cu}$ atoms in a $\mathrm{Cu}$ conventional cell.

To measure the difficulty of $\mathrm{Cu}$ atom migration, the energy barrier $\left(E_{\mathrm{b}}\right)$ was calculated according to the following equation:

$$
E_{\mathrm{b}}=E_{\mathrm{TS}}-E_{\mathrm{IS}}
$$

where $E_{\mathrm{TS}}$ is the total energy of transition state configuration; $E_{\mathrm{IS}}$ is the total energy of the initial configuration.

The Bader charge analysis was performed to quantitatively estimate the charge state of the $\mathrm{Cu}$ atoms in $\mathrm{Cu}-\mathrm{SA} / \mathrm{Ti}_{3} \mathrm{C}_{2} \mathrm{~T}_{x}$ and $\mathrm{Cu}_{2} \mathrm{O}$.

Transition states of interest were searched by CI-NEB method with an electron step convergence criterion of $10^{-8} \mathrm{eV}$.

\section{Data availability}

The data that support the findings of this study are available within the article (and its Supplementary Information files) and from the corresponding authors upon reasonable request.

Received: 16 February 2020; Accepted: 26 November 2020; Published online: 11 January 2021

\section{References}

1. Jouny, M., Hutchings, G. S. \& Jiao, F. Carbon monoxide electroreduction as an emerging platform for carbon utilization. Nat. Catal. 2, 1062-1070 (2019).

2. $\mathrm{Lu}, \mathrm{Q}$. et al. A selective and efficient electrocatalyst for carbon dioxide reduction. Nat. Commun. 5, 3242 (2014).

3. Mou, S. et al. Boron phosphide nanoparticles: a nonmetal catalyst for highselectivity electrochemical reduction of $\mathrm{CO}_{2}$ to $\mathrm{CH}_{3} \mathrm{OH}$. Adv. Mater. 31, 1903499 (2019).

4. Ji, L. et al. Highly selective electrochemical reduction of $\mathrm{CO}_{2}$ to alcohols on an FeP nanoarray. Angew. Chem. Int. Ed. 59, 758-762 (2020).

5. Li, C. W., Ciston, J. \& Kanan, M. W. Electroreduction of carbon monoxide to liquid fuel on oxide-derived nanocrystalline copper. Nature 508, 504-507 (2014).

6. Cuellar, N. R., Wiesner-Fleischer, K., Fleischer, M., Rucki, A. \& Hinrichsen, O. Advantages of $\mathrm{CO}$ over $\mathrm{CO}_{2}$ as reactant for electrochemical reduction to ethylene, ethanol and n-propanol on gas diffusion electrodes at high current densities. Electrochim. Acta 307, 164-175 (2019).

7. Zheng, T., Jiang, K. \& Wang, H. Recent advances in electrochemical $\mathrm{CO}_{2^{-}}$ ecent conversion on heterogeneous catalysts. Adv. Mater. 30, 1802066 (2018).

8. Ripatti, D. S., Veltman, T. R. \& Kanan, M. W. Carbon monoxide gas diffusion electrolysis that produces concentrated $\mathrm{C}_{2}$ products with high single-pass conversion. Joule 3, 240-256 (2019).

9. Jouny, M., Luc, W. \& Jiao, F. High-rate electroreduction of carbon monoxide to multi-carbon products. Nat. Catal. 1, 748-755 (2018).

10. Raciti, D. et al. Low-overpotential electroreduction of carbon monoxide using copper nanowires. ACS Catal. 7, 4467-4472 (2017).

11. Zhang, H., Li, J., Cheng, M.-J. \& Lu, Q. CO electroreduction: current development and understanding of Cu-based catalysts. ACS Catal. 9, 49-65 (2018).

12. Luc, W. et al. Two-dimensional copper nanosheets for electrochemical reduction of carbon monoxide to acetate. Nat. Catal. 2, 423-430 (2019).

13. Li, J. et al. Effectively increased efficiency for electroreduction of carbon monoxide using supported polycrystalline copper powder electrocatalysts. ACS Catal. 9, 4709-4718 (2019).

14. Jiang, $\mathrm{K}$. et al. Metal ion cycling of $\mathrm{Cu}$ foil for selective $\mathrm{C}-\mathrm{C}$ coupling in electrochemical $\mathrm{CO}_{2}$ reduction. Nat. Catal. 1, 111-119 (2018).

15. Dinh, C.-T. et al. $\mathrm{CO}_{2}$ electroreduction to ethylene via hydroxide-mediated copper catalysis at an abrupt interface. Science 360, 783-787 (2018).

16. $\mathrm{Mi}$, Y. et al. Selective electroreduction of $\mathrm{CO}_{2}$ to $\mathrm{C}_{2}$ products over $\mathrm{Cu}_{3}$ Nproducts ovenanowires. ChemElectroChem 6, 2393-2397 (2019)

17. $\mathrm{Ma}, \mathrm{S}$. et al. Electroreduction of carbon dioxide to hydrocarbons using bimetallic $\mathrm{Cu}-\mathrm{Pd}$ catalysts with different mixing patterns. J. Am. Chem. Soc. 139, 47-50 (2017)

18. Cheng, T., Xiao, H. \& Goddard, W. A. Nature of the active sites for $\mathrm{CO}$ reduction on copper nanoparticles: suggestions for optimizing performance. J. Am. Chem. Soc. 139, 11642-11645 (2017).
19. Malkani, A. S., Dunwell, M. \& Xu, B. Operando spectroscopic investigations of copper and oxide-derived copper catalysts for electrochemical $\mathrm{CO}$ reduction. ACS Catal. 9, 474-478 (2018).

20. Zhang, B. W., Wang, Y. X., Chou, S. L., Liu, H. K. \& Dou, S. X. Fabrication of superior single-atom catalysts toward diverse electrochemical reactions. Small Methods 3, 1800497 (2019).

21. Lü, F. et al. Nitrogen-coordinated single Fe sites for efficient electrocatalytic $\mathrm{N}_{2}$ fixation in neutral media. Nano Energy 61, 420-427 (2019).

22. Lü, F. et al. Electrochemical $\mathrm{CO}_{2}$ reduction: from nanoclusters to single atom catalysts. Sustain. Energy Fuels 4, 1012-1028 (2020).

23. Yang, $\mathrm{H}$. et al. Scalable production of efficient single-atom copper decorated carbon membranes for $\mathrm{CO}_{2}$ electroreduction to methanol. J. Am. Chem. Soc. 141, 12717-12723 (2019).

24. Song, B. et al. Two-dimensional anti-Van't Hoff/Le Bel array $\mathrm{AlB}_{6}$ with high stability, unique motif, triple Dirac cones, and superconductivity. J. Am. Chem. Soc. 141, 3630-3640 (2019).

25. Yang, L.-M. et al. Two-dimensional $\mathrm{Cu}_{2} \mathrm{Si}$ monolayer with planar hexacoordinate copper and silicon bonding. J. Am. Chem. Soc. 137, 2757-2762 (2015).

26. Liu, J.-H., Yang, L.-M. \& Ganz, E. Efficient and selective electroreduction of $\mathrm{CO}_{2}$ by single-atom catalyst two-dimensional TM-Pc monolayers. ACS Sustain. Chem. Eng. 6, 15494-15502 (2018).

27. Liu, J.-H., Yang, L.-M. \& Ganz, E. Electrochemical reduction of $\mathrm{CO}_{2}$ by single atom catalyst TM-TCNQ monolayers. J. Mater. Chem. A 7, 3805-3814 (2019).

28. Liu, J.-H., Yang, L.-M. \& Ganz, E. Electrochemical reduction of $\mathrm{CO}_{2}$ by twodimensional transition metal porphyrin sheets. J. Mater. Chem. A 7, 11944-11952 (2019).

29. Liu, J.-H., Yang, L.-M. \& Ganz, E. Efficient electrocatalytic reduction of carbon dioxide by metal-doped $\beta 12$-borophene monolayers. RSC Adv. 9, 27710-27719 (2019).

30. Liu, J.-H., Yang, L.-M. \& Ganz, E. Two-dimensional organometallic TM3-C12S12 monolayers for electrocatalytic reduction of $\mathrm{CO}_{2}$. Energy Environ. Mater. 2, 193-200 (2019).

31. Naguib, M. et al. Two-dimensional nanocrystals produced by exfoliation of $\mathrm{Ti}_{3} \mathrm{AlC}_{2}$. Adv. Mater. 23, 4248-4253 (2011).

32. Naguib, M., Mochalin, V. N., Barsoum, M. W. \& Gogotsi, Y. 25th anniversary article: MXenes: a new family of twoof Ti metal-doped $\beta 12$-b. Adv. Mater. 26, 992-1005 (2014).

33. Alhabeb, M. et al. Guidelines for synthesis and processing of two-dimensional titanium carbide $\left(\mathrm{Ti}_{3} \mathrm{C}_{2} \mathrm{~T}_{x}\right.$ MXene). Chem. Mater. 29, 7633-7644 (2017).

34. Zhao, D. et al. MXene $\left(\mathrm{Ti}_{3} \mathrm{C}_{2}\right)$ vacancy-confined single-atom catalyst for efficient functionalization of $\mathrm{CO}_{2}$. J. Am. Chem. Soc. 141, 4086-4093 (2019).

35. Zhao, S. et al. Isolated single-atom Pt sites for highly selective electrocatalytic hydrogenation of formaldehyde to methanol. J. Mater. Chem. A 8, 8913-8919 (2020).

36. Liu, X. et al. Nanoporous $\mathrm{Zn}$-doped $\mathrm{Co}_{3} \mathrm{O}_{4}$ sheets with single-unit-cell-wide lateral surfaces for efficient oxygen evolution and water splitting. Nano Energy 44, 371-377 (2018).

37. Garcia, A. et al. Polymer grafting by inkjet printing: a direct chemical writing toolset. Adv. Funct. Mater. 23, 3668-3674 (2013).

38. Kumar, M., Satpati, B. \& Som, T. Revealing multimode resistive switching in $\mathrm{Cu}-\mathrm{O}$ nanostructures using conductive atomic force microscopy. Appl. Surf. Sci. 454, 82-86 (2018).

39. Gu, J., Hsu, C.-S., Bai, L., Chen, H. M. \& Hu, X. Atomically dispersed Fe ${ }^{3+}$ sites catalyze efficient $\mathrm{CO}_{2}$ electroreduction to $\mathrm{CO}$. Science 364, 1091-1094 (2019).

40. Liu, P. et al. Photochemical route for synthesizing atomically dispersed palladium catalysts. Science 352, 797-800 (2016).

41. Karapinar, D. et al. Electroreduction of $\mathrm{CO}_{2}$ on single-site copper-nitrogendoped carbon material: selective formation of ethanol and reversible restructuration of the metal sites. Angew. Chem. Int. Ed. 58, 15098-15103 (2019).

42. Wang, L. et al. Electrochemically converting carbon monoxide to liquid fuels by directing selectivity with electrode surface area. Nat. Catal. 2, 702-708 (2019).

43. Pang, Y. et al. Efficient electrocatalytic conversion of carbon monoxide to propanol using fragmented copper. Nat. Catal. 2, 251-258 (2019).

44. Chen, R. et al. Highly selective production of ethylene by the electroreduction of carbon monoxide. Angew. Chem. Int. Ed. 59, 154-160 (2020).

45. Han, Z., Kortlever, R., Chen, H.-Y., Peters, J. C. \& Agapie, T. $\mathrm{CO}_{2}$ reduction selective for $\mathrm{C} \geq 2$ products on polycrystalline copper with $\mathrm{N}$-substituted pyridinium additives. ACS Cent. Sci. 3, 853-859 (2017).

46. Crowley, S. \& Castaldi, M. J. Mechanistic insights into catalytic ethanol steam reforming using isotope-labeled reactants. Angew. Chem. Int. Ed. 55, 10650-10655 (2016).

47. Lum, Y. \& Ager, J. W. Evidence for product-specific active sites on oxidederived $\mathrm{Cu}$ catalysts for electrochemical $\mathrm{CO}_{2}$ reduction. Nat. Catal. 2, 86-93 (2019). 
48. Wang, T. et al. Cu,N-codoped carbon nanodisks with biomimic stomata-like interconnected hierarchical porous topology as efficient electrocatalyst for oxygen reduction reaction. Small 15, 1902410 (2019).

49. Zhang, T. et al. Single atomic $\mathrm{Cu}-\mathrm{N}_{2}$ catalytic sites for highly active and selective hydroxylation of benzene to phenol. iScience 22, 97-108 (2019).

50. Bai, X. et al. Insight into the catalytic activity of MXenes for hydrogen evolution reaction. Sci. Bull. 63, 1397-1403 (2018)

51. Gao, G., O'Mullane, A. P. \& Du, A. 2D MXenes: a new family of promising catalysts for the hydrogen evolution reaction. ACS Catal. 7, 494-500 (2017).

52. Letchworth-Weaver, K. \& Arias, T. Joint density functional theory of the electrode-electrolyte interface: application to fixed electrode potentials, interfacial capacitances, and potentials of zero charge. Phys. Rev. B 86, 075140 (2012).

53. Goodpaster, J. D., Bell, A. T. \& Head-Gordon, M. Identification of possible pathways for $\mathrm{C}-\mathrm{C}$ bond formation during electrochemical reduction of $\mathrm{CO}_{2}$ : new theoretical insights from an improved electrochemical model. J. Phys. Chem. Lett. 7, 1471-1477 (2016).

54. Schouten, K. J. P., Qin, Z., Pérez Gallent, E. \& Koper, M. T. Two pathways for the formation of ethylene in $\mathrm{CO}$ reduction on single-crystal copper electrodes. J. Am. Chem. Soc. 134, 9864-9867 (2012).

55. Calle Chem, F. \& Koper, M. T. Theoretical considerations on the electroreduction of $\mathrm{CO}$ to $\mathrm{C}_{2}$ species on $\mathrm{Cu}$ (100) electrodes. Angew. Chem Int. Ed. 52, 7282-7285 (2013).

56. Garza, A. J., Bell, A. T. \& Head-Gordon, M. Mechanism of $\mathrm{CO}_{2}$ reduction at copper surfaces: pathways to $C_{2}$ products. ACS Catal. 8, 1490-1499 (2018).

57. Schouten, K. J. P., Gallent, E. P. \& Koper, M. T. The electrochemical characterization of copper single-crystal electrodes in alkaline media. $J$. Electroanal. Chem. 699, 6-9 (2013).

58. Schouten, K. J. P., Pérez Gallent, E. \& Koper, M. T. Structure sensitivity of the electrochemical reduction of carbon monoxide on copper single crystals. ACS Catal. 3, 1292-1295 (2013).

59. $\mathrm{Li}, \mathrm{Y}$. C. et al. Binding site diversity promotes $\mathrm{CO}_{2}$ electroreduction to ethanol. J. Am. Chem. Soc. 141, 8584-8591 (2019).

60. Kuhl, K. P., Cave, E. R., Abram, D. N. \& Jaramillo, T. F. New insights into the electrochemical reduction of carbon dioxide on metallic copper surfaces. Energy Environ. Sci. 5, 7050-7059 (2012).

61. Hoang, T. T. et al. Nanoporous copper-silver alloys by additive-controlled electrodeposition for the selective electroreduction of $\mathrm{CO}_{2}$ to ethylene and ethanol. J. Am. Chem. Soc. 140, 5791-5797 (2018).

62. Zhang, J. et al. Single platinum atoms immobilized on an MXene as an efficient catalyst for the hydrogen evolution reaction. Nat. Catal. 1, 985-992 (2018).

63. Wang, Y. et al. Adsorption-energy-based activity descriptors for electrocatalysts in energy storage applications. Natl Sci. Rev. 5, 327-341 (2018).

\section{Acknowledgements}

This work was financially supported by the National Key R\&D Program of China (2017YFA0700104), the National Natural Science Foundation of China (22075211,

$51971157,51808037,21601136$, and 51761165012), the Tianjin Science Fund for
Distinguished Young Scholars (19JCJQJC61800), and the Science and Technology Development Fund of Tianjin Education Commission for Higher Education (No. 2018KJ126). The authors acknowledge Beijng PARATERA Tech CO., Ltd. for providing HPC resources that have contributed to the research results reported within this paper The authors also thank Stanford Synchrotron Radiation Lightsource (SSRL) BL7-3 for providing the beam time. R.C. acknowledges support from DOE funded LDRD program and SSRL.

\section{Author contributions}

X.J.L. and X.P.S. proposed and designed the electrocatalysts. H.H.B., Y.Q., and X.Y.P. cosynthesized the catalyst samples and carried out the electrochemical measurements, to which Y.Y.M. and J.Q.S. assisted. Y.Q., J.A.W., and S.Z.Z. conducted the DFTcalculations. R.C. performed the XAS experiments. H.H.B., X.Y.P., and Y.F.L. analyzed the XAS results. J.Q.R. and L.C.Z. assisted in analyzing the experimental data. X.J.L., J.L., and X.P.S. co-performed the experimental design and the mechanism analysis, and they co-supervised the whole project. All authors discussed the results.

\section{Competing interests}

The authors declare no competing interests.

\section{Additional information}

Supplementary information is available for this paper at https://doi.org/10.1038/s41467020-20336-4.

Correspondence and requests for materials should be addressed to X.L., R.C. or X.S.

Peer review information Nature Communications thanks Liming Yang and the other, anonymous, reviewer(s) for their contribution to the peer review of this work. Peer reviewer reports are available.

\section{Reprints and permission information is available at http://www.nature.com/reprints}

Publisher's note Springer Nature remains neutral with regard to jurisdictional claims in published maps and institutional affiliations.

pen Access This article is licensed under a Creative Commons Attribution 4.0 International License, which permits use, sharing, adaptation, distribution and reproduction in any medium or format, as long as you give appropriate credit to the original author(s) and the source, provide a link to the Creative Commons license, and indicate if changes were made. The images or other third party material in this article are included in the article's Creative Commons license, unless indicated otherwise in a credit line to the material. If material is not included in the article's Creative Commons license and your intended use is not permitted by statutory regulation or exceeds the permitted use, you will need to obtain permission directly from the copyright holder. To view a copy of this license, visit http://creativecommons.org/ licenses/by/4.0/.

(C) The Author(s) 2021 